\title{
Learning, techniques, and complications of endoscopic ultrasound (EUS)-guided sampling in gastroenterology: European Society of Gastro- intestinal Endoscopy (ESGE) Technical Guideline
}

Authors

Institutions
M. Polkowski ${ }^{1}$, A. Larghi' ${ }^{2}$, B. Weynand ${ }^{3}$, C. Boustière ${ }^{4}$, M. Giovannini ${ }^{5}$, B. Pujol ${ }^{6}$, J.-M. Dumonceau ${ }^{7}$

Institutions are listed at the end of article. submitted 10. May 2011 accepted after revision 10. October 2011

\section{Bibliography}

Dol http://dx.doi.org/

10.1055/s-0031-1291543

Published online: 16.12 .2011

Endoscopy 2012; 44: 190-205

(c) Georg Thieme Verlag KG

Stuttgart · New York

ISSN 0013-726X

Corresponding author

M. Polkowski, MD

Department of

Gastroenterology,

The M. Sklodowska-Curie

Memorial Cancer Center and

Institute of Oncology,

Roentgena 5

02-781 Warsaw

Poland

Fax: +48-22-5463035

mp.polkowski@gmail.com
This article is the second of a two-part publication that expresses the current view of the European Society of Gastrointestinal Endoscopy (ESGE) about endoscopic ultrasound (EUS)-guided sampling, including EUS-guided fine needle aspiration (EUS-FNA) and EUS-guided Trucut biopsy. The first part (the Clinical Guideline) focused on the results obtained with EUS-guided sampling, and the role of this technique in patient management, and made recommendations on circumstances that warrant its use. The current Technical Guideline discusses issues related to learning, techniques, and complications of EUS-guided sampling, and to processing of specimens. Technical issues related to maximizing the diagnostic

\section{Introduction}

$\nabla$

The current Technical Guideline discusses issues related to the learning, techniques, and complications of endoscopic ultrasound (EUS)-guided sampling and to processing of specimens obtained with EUS-guided fine needle aspiration (EUSFNA) or EUS-guided Trucut biopsy (EUS-TCB). The results of EUS-guided sampling in various clinical indications, the role of this technique in patient management, and recommendations on its use are discussed in the associated Clinical Guideline from the European Society of Gastrointestinal Endoscopy (ESGE) [1].

\section{Methods}

The ESGE commissioned and funded this Guideline. The method for guideline development was similar to that used for other ESGE Guidelines $[2,3]$. Briefly, subgroups were formed, each charged with a series of clearly defined key questions (see $\bullet$ Appendix e1, available online). The committee chair worked with subgroup leaders to identify pertinent search terms that always in- yield (e.g., rapid on-site cytopathological evaluation, needle diameter, microcore isolation for histopathological examination, and adequate number of needle passes) are discussed and recommendations are made for various settings, including solid and cystic pancreatic lesions, submucosal tumors, and lymph nodes. The target readership for the Clinical Guideline mostly includes gastroenterologists, oncologists, internists, and surgeons while the Technical Guideline should be most useful to endoscopists who perform EUS-guided sampling. A two-page executive summary of evidence statements and recommendations is provided.

cluded, as a minimum, "endoscopic ultrasonography" and words pertinent to specific key questions. Evidence tables were generated for each key question based on meta-analyses or randomized controlled trials (RCTs) if these were available; otherwise, case - control studies, retrospective analyses, and case series were included. The number of articles retrieved and selected for each task force is indicated in the Evidence table (see Appendix e2, available online). Evidence levels and recommendation grades used in these guidelines were those recommended by the amended Scottish Intercollegiate Guidelines Network (SIGN) ( Table 1) [4]. Subgroups agreed electronically on draft proposals that were presented to the entire group for general discussion during two meetings held in 2010 and 2011. The subsequent Guideline version was discussed using electronic mail until unanimous agreement was reached. Searches were re-run in February 2011 (this date should be taken into account for future updates). The final draft was approved by all members of the Guideline development group; it was sent to all individual ESGE members in April 2011 and, after incorporation of their comments, it was endorsed by the ESGE Governing 
Table 1 Definitions of categories for evidence levels and recommendation grades used in this guideline [4].

\begin{tabular}{|c|c|}
\hline \multicolumn{2}{|c|}{ Evidence level } \\
\hline $1++$ & $\begin{array}{l}\text { High quality meta-analyses, systematic reviews of RCTs, or RCTs } \\
\text { with a very low risk of bias }\end{array}$ \\
\hline $1+$ & $\begin{array}{l}\text { Well conducted meta-analyses, systematic reviews of RCTs, or } \\
\text { RCTs with a low risk of bias }\end{array}$ \\
\hline $1-$ & $\begin{array}{l}\text { Meta-analyses, systematic reviews, or RCTs with a high risk of } \\
\text { bias }\end{array}$ \\
\hline $2++$ & $\begin{array}{l}\text { High quality systematic reviews of case - control or cohort } \\
\text { studies; high quality case - control studies } \\
\text { or cohort studies with a very low risk of confounding, bias, or } \\
\text { chance and a high probability that the relationship is causal }\end{array}$ \\
\hline $2+$ & $\begin{array}{l}\text { Well conducted case - control or cohort studies with a low risk } \\
\text { of confounding, bias, or chance and a moderate probability that } \\
\text { the relationship is causal }\end{array}$ \\
\hline $2-$ & $\begin{array}{l}\text { Case-control or cohort studies with a high risk of confounding, } \\
\text { bias, or chance and a significant risk that the relationship is not } \\
\text { causal }\end{array}$ \\
\hline 3 & Nonanalytic studies, e.g. case reports, case series \\
\hline 4 & Expert opinion \\
\hline \multicolumn{2}{|r|}{ Recommendation grades } \\
\hline A & $\begin{array}{l}\text { At least one meta-analysis, systematic review, or RCT rated as } \\
1++ \text { and directly applicable to the target population } \\
\text { or a systematic review of RCTs } \\
\text { or a body of evidence consisting principally of studies rated } \\
\text { as } 1+\text { directly applicable to the target population and demon- } \\
\text { strating overall consistency of results }\end{array}$ \\
\hline B & $\begin{array}{l}\text { A body of evidence including studies rated as } 2++ \text { directly } \\
\text { applicable to the target population and demonstrating overall } \\
\text { consistency of results } \\
\text { or extrapolated evidence from studies rated as } 1++ \text { or } 1+\end{array}$ \\
\hline C & $\begin{array}{l}\text { A body of evidence including studies rated as } 1-\text { or } 2+\text { directly } \\
\text { applicable to the target population and demonstrating overall } \\
\text { consistency of results } \\
\text { or extrapolated evidence from studies rated as } 2++\end{array}$ \\
\hline D & $\begin{array}{l}\text { Evidence level } 2-, 3 \text { or } 4 \\
\text { or extrapolated evidence from studies rated as } 2+\end{array}$ \\
\hline
\end{tabular}

RCT, randomized controlled trial

Board prior to submission to Endoscopy for international peer review. The final revised version was approved by all members of the Guideline development group before publication.

Evidence statements and recommendations are stated in italics, key evidence statements and recommendations are in bold. This Guideline will be considered for review in 2014, or sooner if important new evidence becomes available. Any updates to the Guideline in the interim period will be noted on the ESGE website: http://www.esge.com/esge-guidelines.html.

\section{Summary of statements and recommendations}

\section{$\nabla$}

\section{Learning EUS-FNA}

EUS-FNA is an extension of EUS; all endoscopists who reported their learning curve for EUS-FNA had prior experience in EUS. Material available for learning EUS-FNA includes common didactic material (e.g., books, videos), various types of simulators, and live pigs. Among models available for "hands-on" training, live pigs are the most realistic and could allow the improvement of EUS-FNA skills but are not widely available. The learning process of EUS-FNA has been studied for solid pancreatic lesions only; it showed a learning curve with increasing sensitivity for the cytopathological diagnosis of cancer (reaching 80\% after 20-30 EUS-FNA), decreasing number of passes needed to obtain adequate results (reaching a median of 3 after 150 EUS-FNA), but no variation in severe morbidity. In all reported studies, rapid on-site cytopathological examination (ROSE) was used to guide the number of FNA passes needed (Evidence level $2+)$.

Trainees should demonstrate competence in linear EUS before undertaking EUS-FNA. We discourage self-learning of EUS-FNA. We recommend combination of the use of different simulators and, if available, live pigs, during training in EUS-FNA. We recommend that a minimum of 20 and 30 supervised EUS-FNAs of nonpancreatic and pancreatic lesions, respectively, be performed with ROSE before assessment of competency in these techniques (Recommendation grade C). ROSE is preferable although direct supervision by an endosonographer experienced in EUS-FNA can be another option. Close collaboration with a cytopathologist experienced in evaluation of EUS-FNA samples is recommended (Recommendation grade D).

\section{Techniques of EUS-FNA}

For EUS-FNA of pancreatic lesions the 19G, 22G and $25 G$ needles are characterized by similar diagnostic yields (Evidence level $1+$ ) and safety profiles (Evidence level 1-). Although 19G needles provide a higher amount of cellular material than do thinner needles, and, if technically successful, offer better diagnostic yield, these advantages are offset by a higher rate of technical failures in the case of lesions that need to be punctured from the duodenum (Evidence level 1 -). Studies comparing EUS-FNA needles of different sizes in indications other than pancreatic masses are lacking. We recommend against using $19 \mathrm{G}$ needles for transduodenal biopsy (Recommendation grade $C$ ).

Applying continuous suction with a syringe during EUS-FNA improves the sensitivity for the diagnosis of malignancy in patients with solid masses but not in patients with lymphadenopathy (Evidence level 1 -). We recommend using suction for EUS-FNA of solid masses/cystic lesions and not using suction for EUS-FNA of lymph nodes (Recommendation grade $C$ ).

Using the needle stylet does not seem to impact EUS-FNA sample quality and results (Evidence level 1-). There is insufficient evidence to recommend for or against using the stylet and the decision in this regard should be left to the discretion of the endosonographer performing the procedure (Recommendation grade C).

Diagnostic accuracy of EUS-FNA does not differ depending on whether the sampling is performed from the edge of a lymph node or from its center (Evidence level 1-). No data on this topic are available for lesions other than lymph nodes. We recommend sampling all parts of solid lesions or lymph nodes (Recommendation grade C) and sampling any solid component inside pancreatic cysts and the wall of the cyst (Recommendation grade D).

Gross visual inspection is unreliable in assessing the adequacy of EUS-FNA specimens for cytopathological examination. ROSE provides a highly reliable diagnosis with an excellent agreement with the final cytopathological diagnosis (Evidence level 2+). There is limited evidence to suggest that ROSE increases the diagnostic yield of EUS-FNA (Evidence level 2-). The diagnostic yield of EUS-FNA with ROSE in most studies exceeds $90 \%$; however, similarly good results have been reported from selected studies without ROSE. (Evidence level 2+). Data on cost-effectiveness of ROSE are very limited. In view of these data, it is felt that implementation of ROSE should be considered especially during the learning phase of EUSFNA and at centers in which specimen adequacy rates are below 90\% (Recommendation grade D). 
Various studies have investigated the adequate number of needle passes that should be performed if ROSE is not used. Discordant conclusions have been reached for solid masses, while more concordant results have been reported for lymph nodes, liver lesions, and pancreatic cysts. We recommend performing 3 needle passes for lymph nodes and liver lesions, at least 5 needle passes for solid pancreatic masses, and a single pass for pancreatic cysts (Recommendation grade $\mathrm{C}$ ).

\section{Techniques to obtain tissue for histopathological evaluation}

EUS-FNA with standard needles can provide tissue adequate for histopathological evaluation from most pancreatic tumors (Evidence level $2+$ ). Combining EUS-FNA histology and EUS-FNA cytology seems to increase EUS-FNA diagnostic yield (Evidence level 2-) and sensitivity for pancreatic cancer detection (Evidence level 2+). Other potential advantages of EUS-FNA histology consist of facilitated immunostaining and better capability to diagnose specific tumor types (Evidence level 2-). We suggest implementation of this technique into routine practice (Recommendation grade $D$ ).

Transduodenal EUS-TCB is characterized by a very high failure rate (Evidence level $2+$ ). For non-transduodenal routes, the failure rate is low and the accuracy for the detection of malignancy is similar to that of EUS-FNA (Evidence level 2+). The accuracy of dual sampling $(E U S-T C B+E U S-F N A)$ is superior to either technique alone (Evidence level $2+$ ). Sequential sampling (EUS-TCB with EUS-FNA rescue) has similar accuracy to that of dual sampling (Evidence level $2-$ ). EUS-TCB is superior to EUS-FNA in establishing some specific diagnoses, especially of benign tumors or if immunostaining is required (Evidence level 2-). In most instances EUS-TCB does not offer advantages over EUS-FNA; however, EUS-TCB should be considered when tissue architectural details and immunostaining are required to establish a specific diagnosis (Recommendation grade C).

\section{Specimen processing}

No adequate study has compared direct smear cytology vs. liquidbased cytology (LBC) for processing specimens collected with EUSFNA. Similarly, no study has evaluated which of the methods described for collecting tissue fragments for histopathological examination is better. In the case of suspected tuberculosis or lymphoma, polymerase chain reaction (suspected tuberculosis) on histopathological specimens and flow cytometry (suspected lymphoma), after placement of the collected specimen in an adequate transport medium have, been shown to significantly increase the diagnostic yield (Evidence level $2+$ ). The specific method to be used for both cytopathological processing and collection of histopathological specimens should be left to the discretion of each center, depending on their confidence with available methods (Recommendation grade D). Cell blocks can be used as a complement to rather than a replacement for smears or LBC (Recommendation grade D). If tuberculosis is suspected, then polymerase chain reaction should be used; if lymphoma is suspected then flow cytometry should be used (Recommendation grade $\mathrm{C}$ ).

\section{Complications of EUS-FNA and their prevention}

EUS-FNA is a safe procedure with a complication rate of approximately $1 \%$ (Evidence level $2++$ ). Complications include infection, bleeding, and acute pancreatitis; they are more frequent for EUSFNA of cystic compared with solid lesions (Evidence level 2-). Bacteremia is rare after EUS-FNA, including that of perirectal and rectal lesions (Evidence level 2++). The 19G, 22G, and 25G EUS-FNA needles present similar complication rates. Transesophageal and transgas- tric EUS-TCB have similar safety profiles compared with EUS-FNA, at least in experienced hands (Evidence level 1-). Aspirin/nonsteroidal anti-inflammatory drugs (NSAIDs) do not seem to increase the risk of bleeding following EUS-FNA (Evidence level 2-).

Antibiotic prophylaxis is recommended before EUS-guided sampling of cystic lesions (Recommendation grade $C$ ) but not of solid lesions (Recommendation grade $B$ ). Antibiotic prophylaxis of infective endocarditis is not recommended (Recommendation grade $B$ ). Coagulation check-up is recommended before EUS-FNA only in patients with a personal or family history suggesting bleeding disorder or with a clear clinical indication (Recommendation grade C). EUS-guided sampling should not be performed in patients treated with oral anticoagulants (Recommendation grade C) or thienopyridines (Recommendation grade D). In addition, treatment with aspirin or NSAIDs is a contraindication for EUS-guided sampling of cystic lesions (Recommendation grade $C$ ).

EUS-TCB is contraindicated for lesions requiring a transduodenal approach, lesions $<20 \mathrm{~mm}$ or of cystic appearance, and when the operator has limited experience with standard EUS-FNA (Recommendation grade $D$ ).

\section{Learning EUS-FNA \\ $\nabla$}

EUS-FNA is an extension of EUS; all endoscopists who reported their learning curve for EUS-FNA had prior experience in EUS. Material available for learning EUS-FNA includes common didactic material (e.g., books, videos), various types of simulators, and live pigs. Among models available for "hands-on" training, live pigs are the most realistic and could allow the improvement of EUS-FNA skills but are not widely available. The learning process of EUS-FNA has been studied for solid pancreatic lesions only; it showed a learning curve with increasing sensitivity for the cytopathological diagnosis of cancer (reaching $80 \%$ after 20 - 30 EUS-FNA), decreasing number of passes needed to obtain adequate results (reaching a median of 3 after 150 EUS-FNA), but no variation in severe morbidity. In all reported studies ROSE was used to guide the number of FNA passes needed (Evidence level $2+$ ).

Trainees should demonstrate competence in linear EUS before undertaking EUS-FNA. We discourage self-learning of EUS-FNA. We recommend combination of the use of different simulators and, if available, live pigs, during training in EUS-FNA. We recommend that a minimum of 20 and 30 supervised EUS-FNA of non-pancreatic and pancreatic lesions, respectively, be performed with ROSE before assessment of competency in these techniques (Recommendation grade C). ROSE is preferable although direct supervision by an endosonographer experienced in EUS-FNA can be another option. Close collaboration with a cytopathologist experienced in evaluation of EUS-FNA samples is recommended (Recommendation grade $D)$.

\subsection{Training in EUS-FNA}

The results of two methods for learning EUS-FNA have been reported, i.e. formal training, consisting of fellowship in a dedicated training center for 6-24 months, and informal training, consisting of short repeated exposures to various didactic situations that usually included short "hands-on" experiences [5]. Formal training programs are scarce in Europe and even in countries where they are most developed (e.g., France), they allow training of only a small number of endoscopists per year [6-8]. In addition, the long duration of formal training programs is impractical for the practicing, experienced endoscopist. The proportion of 
Table 2 Series reporting the learning curve for endoscopic ultrasound (EUS)-guided fine needle aspiration (FNA) of solid pancreatic lesions.

\begin{tabular}{|c|c|c|c|c|c|c|}
\hline $\begin{array}{l}\text { First author, } \\
\text { year }\end{array}$ & $\begin{array}{l}\text { Patients/ } \\
\text { operators, n/n }\end{array}$ & $\begin{array}{l}\text { Operator } \\
\text { experience prior } \\
\text { to study period }\end{array}$ & Training: type, duration & $\begin{array}{l}\text { Sensitivity for } \\
\text { cancer diagnosis: } \\
\text { First vs. last FNA } \\
\text { series compared }\end{array}$ & Complications & $\begin{array}{l}\text { FNAs needed to } \\
\text { reach } 80 \% \\
\text { sensitivity for } \\
\text { cancer diagnosis, } \\
\text { n }\end{array}$ \\
\hline $\begin{array}{l}\text { Harewood, } \\
2002 \text { [15] }\end{array}$ & $65 / 3$ & $\begin{array}{l}>300 \text { EUS } \\
<10 \text { EUS-FNA }\end{array}$ & Informal' 1 , 2 months & $44 \%$ vs. $91 \%$ & No data & 20 \\
\hline $\begin{array}{l}\text { Mertz, } 2004 \\
\text { [14] }\end{array}$ & $57 / 1$ & $\begin{array}{l}132 \text { EUS } \\
\text { No EUS-FNA }\end{array}$ & Informal ${ }^{1}$, no data & $50 \%$ vs. $80 \%$ & 0 & 30 \\
\hline $\begin{array}{l}\text { Eloubeidi, } 2005 \\
\text { [13] }\end{array}$ & $300 / 1$ & $\begin{array}{l}316 \text { EUS } \\
45 \text { EUS-FNA }\end{array}$ & Formal, 1 year & $92 \%$ vs. $95 \%$ & $13 \%^{2}$ & No data \\
\hline
\end{tabular}

${ }^{1}$ Mentoring during the performance of 2 to 10 pancreatic EUS-FNAs by an experienced endosonographer

2 Including major complications (oversedation that required the administration of a reversal agent or hospitalization or emergency department visit) in $2 \%$ of patients

endosonographers who report that they are self-taught varies between $8 \%$ and $50 \%$ [9-11]. Although unalloyed self-education is feasible for simple endoscopic procedures while maintaining high quality and safety standards [12], it has not been reported for more complex procedures such as EUS-FNA [5].

It seems reasonable to assume that any training has to be founded on theoretical and clinical knowledge [7]. Furthermore, all of the endoscopists who reported their learning curve for EUSFNA had performed diagnostic EUS before performing supervised EUS-FNA [13-15]. Competence in percutaneous abdominal ultrasound is not a prerequisite for EUS or EUS-FNA because no evidence was found in the literature that it improves competence in EUS. Criteria useful for assessing whether competence in EUS has been reached are available [16].

The use of textbooks and videos is recommended in most consensus statements as a basis for EUS training. Hands-on training in EUS-FNA has used: (i) phantoms devoid of animal material (Olympus, Tokyo, Japan; self-made phantoms constructed with commonly available materials); (ii) models using porcine organs (upper and lower digestive EUS-FNA) [17-19]; and (iii) live pigs [20]. Simulators (www.simbionix.com) do not currently offer training in FNA. All of these models have been subjected to feasibility studies only, except for the live pig model. The latter was evaluated during a 4-week EUS course: a significant improvement was noted in terms of duration and precision of the procedure between the first and second attempt at FNA of lymph nodes at the liver hilum [6]. This model was judged by eight EUS experts as the most realistic and useful for teaching EUS-FNA, but the least easy to incorporate into fellowship training [18]. These experts recommended using different learning tools at different time periods during the learning curve for EUS and EUS-FNA. A model using porcine organs was preferred over both live pigs and phantoms devoid of animal material.

\subsection{Learning curve of EUS-FNA}

Five endosonographers have reported their learning curve for EUS-FNA of solid pancreatic lesions, the procedure considered to be the most complex ( Table 2) [13-16]. All endosonographers had performed a minimum of 132 - 300 diagnostic EUS prior to EUS-FNA, and had participated in a formal or informal training program, and they used ROSE to guide the number of FNA passes. For the cytopathological diagnosis of pancreatic cancer, sensitivity increased with the operator's experience and reached $80 \%$ after 20 to 30 EUS-FNA (including operator's experience prior to the study if applicable). ROSE may be useful to guide the number of FNA passes, learn which parts of the lesion may be targeted for increased diagnostic yield, and correct technical errors (e.g., bloody or paucicellular material) $[21,22]$.

The American Society of Gastrointestinal Endoscopy has reapproved in November 2008 its recommendations that competency should be assessed separately for pancreatic and non-pancreatic EUS-FNA, after at least 25 supervised procedures of each type [16]. For all endoscopy procedures, substantial variations exist between individuals with regard to the speed of learning [23], so that this number should be considered to be the minimum before evaluating the trainee. In addition, as shown by Eloubeidi et al., the learning curve continues long after EUS fellowship.In a prospective study evaluating 300 EUS-FNA performed by a single endosonographer, who had performed 45 supervised procedures during a training period before the study period, the proportion of EUS-FNA that required $\geq 5$ passes significantly decreased after 100 additional procedures and the complication rate decreased after 200 additional procedures (most of these complications were graded as minor) [13].

\section{Techniques of EUS-FNA}

Needles for sampling under EUS guidance are available from four manufacturers ( Table 3). Most models are intended for aspirating cellular material for cytopathological examination. Tissue fragments suitable for histopathological examination can be obtained using standard 19G or 22G FNA needles as well as with dedicated histopathological needles (e.g. Trucut, ProCore). The following sections discuss various technical issues related to EUS-FNA and EUS-TCB. For detailed expert instruction on how to perform step-by-step EUS-FNA and EUS-TCB, readers are referred to other sources [24-26].

\subsection{Does the diameter of EUS-FNA needle matter?}

For EUS-FNA of pancreatic lesions, the 19G, 22G and 25G needles are characterized by similar diagnostic yields (Evidence level 1+) and safety profiles (Evidence level 1-). Although $19 \mathrm{G}$ needles provide a higher amount of cellular material than do thinner needles, and, if technically successful, offer a better diagnostic yield, these advantages are offset by a higher rate of technical failures in the case of lesions that need to be punctured from the duodenum (Evi- 


\begin{tabular}{|c|c|c|c|}
\hline Manufacturer Model & Needle type & Needle diameter & Single-use vs. reusable \\
\hline \multicolumn{4}{|l|}{ Boston Scientific } \\
\hline Expect & Aspiration needle & 19G, 22G, 25G & Single-use \\
\hline Expect Flex & Aspiration needle & $19 G$ & Single-use \\
\hline \multicolumn{4}{|l|}{ Cook } \\
\hline Echotip & Aspiration needle & $22 \mathrm{G}$ & Single-use \\
\hline Echotip Ultra & Aspiration needle & 19G, 22G, 25G & Single-use \\
\hline Echotip ProCore ${ }^{1}$ & Aspiration needle with a core trap & 19G, 22G & Single-use \\
\hline QuickCore & Core biopsy needle & $19 G$ & Single-use \\
\hline EchoBrush $^{2}$ & Needle with cytology brush & $19 G$ & Single-use \\
\hline \multicolumn{4}{|l|}{ Mediglobe } \\
\hline Sonotip Pro Control & Aspiration needle & 19G, 22G, 25G & Single-use \\
\hline \multicolumn{4}{|l|}{ Olympus } \\
\hline Power-Shot ${ }^{3}$ & Aspiration needle & $22 \mathrm{G}$ & Reusable \\
\hline EZ-Shot ${ }^{3}$ & Aspiration needle & $22 \mathrm{G}$ & Single-use \\
\hline EZ-Shot 2 & Aspiration needle & 19G, 22G, 25G & Single-use \\
\hline EZ-Shot 2 with sideport ${ }^{4}$ & Aspiration needle with sideport & $22 \mathrm{G}$ & Single-use \\
\hline
\end{tabular}

Table 3 Needles for endoscopic ultrasound (EUS)guided sampling.

${ }^{1}$ A newly marketed needle designed with a core trap and reverse bevel technology to increase sampling yield and promote collection of histopathological samples.

${ }^{2}$ A modified stylet with a $1 \times 5$-mm brush at its end; it is designed to pass through a 19G EUS-FNA needle, for brushing the cyst wall.

${ }^{3}$ Compatible exclusively with Olympus endoscopes.

${ }^{4} \mathrm{~A}$ newly marketed needle designed with a sideport to draw tissue from both the tip and side of the needle.

dence level 1 - ). Studies comparing EUS-FNA needles of different sizes in indications other than pancreatic masses are lacking.

We recommend against using $19 G$ needles for transduodenal biopsy (Recommendation grade $C$ ).

Most of the studies on EUS - FNA have been conducted using 22G needles. Data on thinner (25G) or larger (19G) needles are limited. A number of recent studies, including two RCTs, compared results obtained with needles of various diameters. All these studies were performed in the setting of pancreatic masses [2731].

It has been suggested that although thinner needles provide less cellular material than do larger needles, the specimens from the former are less contaminated by blood, and thus easier to interpret. In addition, thinner needles may be easier to use because of greater flexibility, particularly for locations requiring important scope bending $[30,31]$. This preliminary evidence was only partly confirmed in further research.

In a small prospective, non-randomized study in 24 patients, the technical success rate for the $25 \mathrm{G}$ needle was significantly higher than for the $22 \mathrm{G}$ needle, but only for tumors located in the uncinate process [29].

An RCT in 131 patients found no significant differences between $22 \mathrm{G}$ and $25 \mathrm{G}$ needles in terms of diagnostic yield for malignancy, number of needle passes needed to obtain a diagnosis, ease of needle passage into the mass, and rates of needle malfunction and of complications [27]. ROSE was used in this study.

Another RCT compared EUS-FNA without ROSE using 19G or 22G needles in 117 patients [28]. In the intention-to-treat analysis, diagnostic accuracy was similar for both needles. However, if technical failures were excluded (per-protocol analysis), diagnostic accuracy was higher with the $19 \mathrm{G}$ compared to the $22 \mathrm{G}$ needle ( $95 \%$ vs. 79\%, respectively; $P=0.015$ ). Technical failures were reported only for $19 \mathrm{G}$ needles in patients with pancreatic head masses (in $19 \%$ of cases). The $19 \mathrm{G}$ needle provided a higher amount of cellular material with fewer passes ( $2.4 \mathrm{vs}$. 2.8 ; respectively; $P=0.01)$. No complications were observed in either group.

\subsection{Should suction be applied during EUS-FNA?}

Applying continuous suction with a syringe during EUS-FNA improves the sensitivity for the diagnosis of malignancy in patients with solid masses but not in patients with lymphadenopathy (Evidence level 1 -). We recommend using suction for EUS-FNA of solid masses/cystic lesions and not using suction for EUS-FNA of lymph nodes (Recommendation grade $C$ ).

Traditionally, suction is applied during EUS-FNA using a syringe [32]. EUS-FNA without suction has been tested in an attempt to decrease sample bloodiness and to improve accuracy of microscopic examination. Two RCTs have compared EUS-FNA with or without suction, in a total of 95 patients with suspected malignant lymph nodes, pancreatic masses or submucosal tumors (SMTs) $[33,34]$. In a study on 46 patients with lymphadenopathy, applying suction did not improve diagnostic accuracy and worsened specimen bloodiness compared with EUS-FNA without suction [33]. In the other study, however, using suction during EUSFNA of solid masses was associated with a significantly higher sensitivity for cancer diagnosis ( $86 \%$ vs. $67 \%$; $P=0.05$ ) [34]. A pilot trial suggested that applying continuous high pressure suction (using a balloon inflation device) allowed retrieval of tissue samples for histopathological examination in most cases [35].

\subsection{With or without needle stylet?}

Using the needle stylet does not seem to impact EUS-FNA sample quality and results (Evidence level 1-). There is insufficient evidence to recommend for or against using the stylet and the decision in this regard should be left to the discretion of the endosonographer performing the procedure (Recommendation grade $C$ ).

For years the standard approach has been to reinsert the stylet into the needle before every pass to prevent sample contamination by cells from the digestive wall as well as blockage of the needle that would hinder sample aspiration. Recently the value of this measure has been questioned by the results of three studies, including one RCT [36-38]. While these studies found no advantages of using the stylet with regard to the quality of sample obtained or the diagnostic yield of malignancy, they also did not demonstrate any disadvantages of this approach. In addition, two of these studies suffered from significant methodological limitations [37-39]. 


\subsection{Which part of the lesion should be punctured to maximize the diagnostic yield?}

Diagnostic accuracy of EUS-FNA does not differ depending on whether the sampling is performed from the edge of a lymph node or from its center (Evidence level 1-). No data on this topic are available for lesions other than lymph nodes.

We recommend sampling all parts of solid lesions or lymph nodes (Recommendation grade $C$ ) and sampling any solid component inside pancreatic cysts and the wall of the cyst (Recommendation grade $D$ ).

Because malignant masses and lymph nodes may undergo central necrosis, it has been assumed that FNA of the edges of the lesion rather than of the center would increase the diagnostic yield. The study by Wallace et al. in which 46 lymph nodes were punctured found that aspiration from the edge of the lymph node did not increase the likelihood of a correct diagnosis when compared to aspiration from the lymph node center [33]. This issue has not been studied for lesions other than lymph nodes. In practice, the needle is usually "fanned" throughout the lesion to sample all its parts.

Recent research indicates that new techniques such as contrastenhanced EUS and elastography may potentially be useful to select the most suspicious area of a lymph node/tumor for EUS-FNA $[40,41]$.

According to expert opinion, the diagnostic yield of EUS-FNA of pancreatic cysts may be improved by aspirating cells from the cyst wall after having aspirated cyst fluid. Using this method, Rogart et al. collected cellular material adequate for cytopathological assessment in 82 (76.6\%) of 107 cysts [42]. If a cyst wall thickening is present (or solid nodules or a solid component inside the cyst), it is advised to sample these targets before aspirating cyst fluid (this would become more difficult once the cyst has collapsed). A cytology brush can also be introduced into the cyst through a 19G needle to scrape the cyst wall [43-45]. This technique has been shown to increase the cellular and diagnostic yields; however, serious concerns exist about its complication, in particular a high risk of intracystic bleeding $[43,45,46]$.

\subsection{What is the role of ROSE?}

Gross visual inspection is unreliable in assessing the adequacy of EUS-FNA specimens for cytopathological examination. ROSE provides a highly reliable diagnosis with an excellent agreement with the final cytopathological diagnosis (Evidence level 2+). There is limited evidence to suggest that ROSE increases the diagnostic yield of EUS-FNA and accuracy for malignancy detection (Evidence level $2-$ ). The diagnostic yield of EUS-FNA with ROSE in most studies exceeds $90 \%$; however, similarly good results have been reported from selected studies without ROSE. (Evidence level 2+). Data on costeffectiveness of ROSE are very limited.

In view of these data, it is felt that implementation of ROSE should be considered especially during the learning phase of EUS-FNA and at centers in which specimen adequacy rates are below $90 \%$ (Recommendation grade $D$ ).

\subsubsection{Gross visual inspection of the specimen}

In a prospective, double-blind, study that included 37 patients with a solid pancreatic mass, neither trained EUS technologists nor cytotechnologists were able to provide a reliable assessment of specimen adequacy by using gross visual inspection. The agreement between their assessment and the final microscopic assessment by a cytopathologist was only fair, with kappa values of about 0.2 . False-positive assessments occurred for about $30 \%$ of the slides, with the potential consequence of premature procedure termination [47].

\subsubsection{ROSE by a cytopathologist}

ROSE has been evaluated mostly in studies of percutaneous FNA: it is generally accepted that ROSE diagnosis is highly reliable and ROSE is the critical procedure for reducing the number of inadequate diagnoses. In addition, ROSE may reduce costs by decreasing the number of repeat procedures [48-50].

Data on ROSE of EUS-FNA specimens are limited. Based on early reports that suggested that ROSE may increase adequacy rates of EUS-FNA specimens by $10 \%-29 \%[51,52]$, ROSE has been implemented at many EUS centers, especially in the United States [53], and has been used in many important studies on EUS-FNA [5457]. The very high specimen adequacy rates consistently reported in these studies ( $>90 \%-95 \%$ ) have been assumed to be linked to ROSE. However, EUS-FNA with vs. without ROSE has never been compared in an RCT. In addition, as discussed below, there are data to suggest that neither does ROSE guarantee, nor is it essential to achieve high adequacy rates.

Evaluating ROSE accuracy or impact has been the primary focus of a few studies only:

- In a prospective study evaluating 607 EUS-FNA procedures (mostly of pancreatic masses and lymph nodes), the agreement between ROSE and final cytopathological diagnosis was excellent (kappa $=0.84)$ [58]. Compared with the true final diagnosis, accuracies of ROSE and final cytopathological examination were not statistically different $(93.9 \%$ and $95.8 \%$, respectively).

- In a retrospective comparison of EUS-FNA results obtained by one endosonographer in two university hospital centers (with ROSE available in only one of them), unequivocal cytopathological diagnosis was obtained significantly more frequently (78\% vs. $52 \%$; odds ratio [OR], $2.94 ; P=0.001$ ) with a lower rate of unsatisfactory specimens ( $9 \%$ vs. $20 \%$; OR, $0.36 ; P=0.035$ ) at the center where ROSE was available [21]. Because patient populations and indications for EUS-FNA significantly differed between the compared centers, no definite conclusions can be drawn from this study.

- In a prospective multicenter study that evaluated 409 patients, two centers used ROSE whereas the other two did not [59]. The results obtained in these two settings were not significantly different (except for a higher negative predictive value in the subgroup of patients with extraintestinal mass lesions when ROSE was used).

- In a retrospective analysis of risk factors for inadequate EUSFNA specimens in 247 pancreatic tumors and 276 lymph nodes, cytopathological adequacy was significantly higher for lymph nodes ( $96 \%$ vs. $84 \%, P=0.008$ ) but not for pancreatic tumors (99\% vs. $100 \% ; P=1$ ) when an on-site cytotechnologist was present [60].

- A recent retrospective analysis of data from a prospectively maintained database showed that in patients with solid pancreatic masses, ROSE reduced the number of inadequate FNA samples ( $1 \%$ vs. $12.6 \% ; P=0.002$ ) and improved the sensitivity ( $96.2 \%$ vs. $78.2 \% ; P=0.002)$ and overall accuracy $(96.8 \%$ vs. $86.2 \% ; P=0.013$ ) of EUS-guided FNA for the diagnosis of malignancy. In addition, a significantly lower number of needle passes was required when ROSE was used [61]. An important limitation of this study was that patient allocation to study groups (95 patients biopsied with and 87 without ROSE) was 
not random but based on whether on-site cytopathology service was available on a given day of the week.

Of note, many recent studies in which ROSE was not used reported adequacy rates of $>90 \%$, indicating that at high volume centers ROSE is not indispensable to achieve excellent results [60,6264]. On the other hand, the use of ROSE does not unconditionally guarantee EUS-FNA success. In a survey of 21 EUS centers in the United States, the diagnostic rate for malignancy in patients with pancreatic tumors varied widely from center to center, despite the fact that ROSE was used at almost all of them [53].

Little is known on the impact of ROSE on EUS-FNA procedural time and it remains unclear whether using ROSE prolongs the procedure or makes it less time-consuming by reducing the number of needle passes. It is assumed that an average time for obtaining the specimen and performing on-site examination is 15 min per sample [65]. Average time expenditure by the cytopathologist for ROSE of computed tomography (CT)-guided and ultrasound-guided FNA specimens is relatively high (48.7 and 44.4 minutes, respectively; measured from the time the pathologist left the office to the time the pathologist returned to the office after the aspiration procedure and interpretation) [66].

\subsubsection{ROSE by endosonographers}

A prospective double-blind study showed that even endosonographers with special training and extensive experience at reviewing cytopathological material alongside a cytopathologist are less accurate than a cytotechnician in the assessment of specimen adequacy (68\%-76\% for three endosonographers vs. $82 \%$ for a cytotechnician; $P=0.004$ ) and in the diagnosis of malignancy (69\%-72\% for three endosonographers vs. $89 \%$ for a cytotechnician; $P<0.001$ ) [67].

Another study did not find significant differences in specimen adequacy rates, number of needle passes or EUS-FNA performance characteristics in two subsequent 2-year periods in which ROSE was performed by endosonographers (first period) or cytopathologists (second period). The study evaluated only a total of 73 EUS-FNA procedures [68].

\subsection{How many passes should be performed if ROSE is not used?}

Various studies have investigated the adequate number of needle passes that should be performed if ROSE is not used. Discordant conclusions have been reached for solid masses, while more concordant results have been reported for lymph nodes, liver lesions, and pancreatic cysts. We recommend performing 3 needle passes for lymph nodes and liver lesions, at least 5 needle passes for solid pancreatic masses, and a single pass for pancreatic cysts (Recommendation grade $C$ ).

The knowledge of the adequate number of needle passes to be performed to reach a good diagnostic accuracy is of paramount importance in centers where ROSE is not used. Differences exist based on the nature of the target lesion.

\subsubsection{Pancreatic masses}

Erickson et al. found in a large study (95 patients) that a mean of $3.4 \pm 2.2$ needle passes (range, $1-10$ ) were required to make a diagnosis [52]. Well-differentiated pancreatic adenocarcinomas required a higher number of passes $(5.5 \pm 2.7)$ as compared to moderately $(2.7 \pm 1.2)$ and poorly $(2.3 \pm 1.1)$ differentiated tumors. The authors recommended performing 5-6 needle passes for pancreatic masses. In another study of 33 patients ( 9 with cystic lesions), Leblanc et al. found that the sensitivity gradually in- creased from $16.7 \%$ for the first pass to $86.7 \%$ when more than 7 passes were performed [69]. Pellisé Urquiza et al. found in a study in 102 patients that the accuracy of EUS-FNA for pancreatic masses reached a plateau at the 4 th needle pass [65]. More recently, Turner et al. reported in a large cohort of 559 patients with a pancreatic mass that a diagnostic accuracy of about $80 \%$ could be obtained with only 2 to 3 needle passes [70]. A high yield with a mean of 1.88 needle passes was also found in another study, in which the material gathered with a 22-gauge EUS-FNA needle was first evaluated for the presence of small tissue core samples that were placed in formalin for histopathological examination and the rest of the material was sent for cytopathological analysis [63].

\subsubsection{Lymph nodes}

Lymph nodes generally require a lower number of needle passes to obtain an adequate diagnostic accuracy. Apart from the study by Leblanc et al. who recommended performance of at least 5 needle passes, other studies agreed that 3 needle passes were sufficient $[33,52,65,69]$.

\subsubsection{Submucosal tumors}

In the study by Pellisé Urquiza et al., the accuracy of EUS-FNA for intramural lesions in 11 patients increased gradually with each subsequent pass to reach a plateau at the $45 \%$ level after the fourth pass [65]. In another study, conducted in 112 patients, a mean of 5.3 needle passes (range 3-9) was done, with a diagnostic accuracy of $83.9 \%$ when both diagnostic and suspicious samples were considered to be positive [71]. Differently, in a study from Japan on 141 patients, a mean of $2.5 \pm 0.7$ (range $1-5$ ) passes were performed with an overall rate of sample adequacy of $83 \%$ that was significantly better for lesions greater than $2 \mathrm{~cm}$ than for those with a smaller diameter [72]. In the latter two studies, multivariate analysis did not show the number of needle passes to be associated with the adequacy of the collected specimens.

\subsubsection{Miscellaneous and liver lesions}

The numbers of needle passes recommended for miscellaneous and liver lesions are similar to those recommended by different authors for pancreatic masses and lymph nodes, respectively. In particular, Leblanc et al. found that for miscellaneous lesions the sensitivity of EUS-FNA increased from $33 \%$ up to $92 \%$ after 7 passes and did not change with additional passes [69]. For liver lesions, Erickson et al. suggested a good diagnostic accuracy with $2-3$ needle passes, a number which is in agreement with other studies $[52,73,74]$.

\section{Techniques to obtain tissue for histopathological evaluation \\ $\nabla$}

Although cytopathological examination of EUS-FNA specimens allows detection of malignancy, it often cannot provide more specific information that may be necessary for patient management. Potential advantages of tissue specimens include information about tissue architecture and more reliable immunostaining. 
Table 4 Studies in which endoscopic ultrasound-guided fine needle aspiration (EUS-FNA) with standard needles was used to obtain tissue for histopathological evaluation (EUS-FNA histology).

\begin{tabular}{|c|c|c|c|c|c|c|}
\hline \multirow[t]{2}{*}{ First author, year (design) } & \multirow{2}{*}{$\begin{array}{l}\text { Indication for } \\
\text { EUS-FNA }\end{array}$} & \multirow{2}{*}{$\begin{array}{l}\text { Patients, } \\
\text { n }\end{array}$} & \multirow{2}{*}{$\begin{array}{l}\text { Needle size } \\
\text { Number of } \\
\text { passes, } n\end{array}$} & \multicolumn{3}{|c|}{ Specimen adequate for: } \\
\hline & & & & Cytology & Histology & $\begin{array}{l}\text { Either histology or } \\
\text { cytology }\end{array}$ \\
\hline Moller, 2009 (retrospective) [63] & Pancreatic mass & 192 & $\begin{array}{l}22 \mathrm{G} \\
1.88 \text { (mean) }\end{array}$ & $93 \%$ & $87 \%$ & $99 \%$ \\
\hline $\begin{array}{l}\text { Iglesias-Garcia, } 2007 \text { (prospective) } \\
\text { [77] }\end{array}$ & Pancreatic mass & 62 & $\begin{array}{l}22 G \\
2+1^{1}\end{array}$ & $82 \%$ & $84 \%$ & $90.3 \%$ \\
\hline Voss, 2000 (retrospective) [79] & Pancreatic mass & 99 & $\begin{array}{l}22 \mathrm{G} \\
2.7 \text { (mean) }\end{array}$ & - & $74 \%$ & - \\
\hline Papanikolaou, 2008 (prospective) [76] & Various $^{2}$ & 42 & $\begin{array}{l}22 \mathrm{G} \\
2 \text { (median) }\end{array}$ & $62 \%$ & $67 \%$ & $74 \%$ \\
\hline Larghi, 2005 (prospective) [35] & Various $^{2}$ & 27 & $\begin{array}{l}22 \mathrm{G} \\
\text { Single pass }\end{array}$ & - & $96 \%$ & - \\
\hline \multirow[t]{2}{*}{ Turhan, 2010 (prospective) [81] } & $\begin{array}{l}\text { Upper gastrointes- } \\
\text { tinal SMTs }\end{array}$ & 49 & $\begin{array}{l}22 \mathrm{G} \\
3 \text { (median) }\end{array}$ & - & $43 \%$ & - \\
\hline & & 6 & $\begin{array}{l}19 G \\
2 \text { (median) }\end{array}$ & & $100 \%$ & \\
\hline $\begin{array}{l}\text { Yoshida, } 2009 \text { (unclear whether } \\
\text { prospective or retrospective) [75] }\end{array}$ & GIST & 49 & $\begin{array}{l}22 \mathrm{G} \\
\text { Not reported }\end{array}$ & $71 \%$ & $63 \%$ & $82 \%$ \\
\hline Ando, 2002 (prospective) [82] & GIST & 23 & $\begin{array}{l}22 \mathrm{G} \\
2.8 \text { (mean) }\end{array}$ & - & $100 \%$ & - \\
\hline Akahoshi, 2007 (prospective) [83] & SMT & 53 & $\begin{array}{l}22 \mathrm{G} \\
2.4 \text { (mean) }\end{array}$ & - & - & $79 \%$ \\
\hline Yasuda, 2006 (prospective) [78] & Lymphadenopathy & 104 & $\begin{array}{l}19 G \\
2 \text { median }\end{array}$ & - & $100 \%$ & - \\
\hline
\end{tabular}

GIST, gastrointestinal stromal tumor: SMT, submucosal tumor.

1 Two passes for cytology plus third pass for histology.

2 Mostly pancreatic mass (30 cases, $71 \%$ [76]; and 17 cases, 63\% [35]).

${ }^{3}$ Single pass using continuous high negative pressure suction.

\subsection{Should tissue fragments be isolated from EUS-FNA specimens and processed for histology?}

EUS-FNA with standard needles can provide tissue adequate for histopathological evaluation from most pancreatic tumors (Evidence level $2+$ ). Combining EUS-FNA histology and EUS-FNA cytology seems to increase EUS-FNA diagnostic yield (Evidence level 2-) and sensitivity for pancreatic cancer detection (Evidence level $2+$ ). Other potential advantages of EUS-FNA histology consist of facilitated immunostaining and better capability to diagnose specific tumor types (Evidence level 2-).

We suggest implementation of this technique into routine practice (Recommendation grade $D$ ).

There is accumulating evidence that tissue adequate for histopathological assessment can be obtained using standard EUS-FNA in a significant proportion of cases [63,75-79]. This technique (EUS-FNA histology) involves gross visual inspection of the sample to collect minute tissue fragments that are subsequently processed for histopathological examination (see section 7.3, below). EUS-FNA histology has been evaluated mostly in the setting of pancreatic tumors, submucosal tumors (SMTs) and lymphadenopathy of unknown origin ( $\bullet$ Table 4$)$.

\subsubsection{Pancreatic mass}

Tissue adequate for histopathological evaluation can be obtained from $67 \%-86.5 \%$ of pancreatic masses using a single pass or few needle passes with a standard $22 \mathrm{G}$ needle $[63,76,77,79,80]$. Combining EUS-FNA cytology and histology significantly increases the sensitivity for malignancy diagnosis compared to cytology or histology alone ( $82.9 \%$ vs. $68.1 \%$ for cytology [ $P=0.007]$, and $60 \%$ for histology $[P<0.0001]$ ] [63]. FNA histology also showed a trend towards higher accuracy in diagnosing specific tumor types other than adenocarcinoma.

\subsubsection{Submucosal tumors}

Comparative data are lacking, but studies that used EUS-FNA histology alone or combined with EUS-FNA cytology reported a higher diagnostic yield than studies that relied only on cytopathological preparations (cell blocks and especially smears) $[75$, $81-83]$.

\subsubsection{Lymphadenopathy of unknown origin}

In a series of 104 patients with mediastinal or/and abdominal lymphadenopathy of unknown origin, a specimen adequate for histopathological evaluation was obtained in all cases using a 19G needle [78]. Among 50 patients with a diagnosis of lymphoma, subtyping was possible in $88 \%$ of cases.

\subsection{What is the role of EUS-guided Trucut biopsy?}

Transduodenal EUS-TCB is characterized by a very high failure rate (Evidence level 2+). For non-transduodenal routes, the failure rate is low and the accuracy for the detection of malignancy is similar to that of EUS-FNA (Evidence level 2+). The accuracy of dual sampling (EUS-TCB +EUS-FNA) is superior to either technique alone (Evidence level 2+). Sequential sampling (EUS-TCB with EUS-FNA rescue) has similar accuracy to that of dual sampling (Evidence level $2-$ ). EUS-TCB is superior to EUS-FNA in establishing some specific diagnoses, especially benign tumors or if immunostaining is required (Evidence level 2 -). 
Table 5 Studies directly comparing endoscopic ultrasound (EUS)-guided Trucut biopsy (TCB) with EUS-guided fine needle aspiration (FNA) for detection of malignancy.

\begin{tabular}{|c|c|c|c|c|c|}
\hline \multirow[t]{2}{*}{ First author, year (design) } & \multirow{2}{*}{$\begin{array}{l}\text { Indications for biopsy } \\
\text { (Sampling route) }\end{array}$} & \multirow[t]{2}{*}{ Patients, $\mathbf{n}$} & \multicolumn{3}{|c|}{ Diagnostic accuracy for malignancy } \\
\hline & & & EUS-TCB & EUS-FNA $^{1}$ & EUS-FNA + EUS-TCB \\
\hline Gerke, 2010 (prospective RCT) [90] & $\begin{array}{l}\text { Various } \\
\text { (Transesophageal, transgastric, } \\
\text { transrectal) }\end{array}$ & $44 / 36^{2}$ & $88 \%$ & $78 \%$ & - \\
\hline Sakamoto, 2009 (prospective) [29] & $\begin{array}{l}\text { Pancreatic mass } \\
\text { (Transgastric, transduodenal) }\end{array}$ & 24 & $50 \%$ & $79 \%$ & - \\
\hline Kipp, 2009 (retrospective) [94] & $\begin{array}{l}\text { Mediastinal/abdominal lesion } \\
\text { (Not reported) }\end{array}$ & 86 & $77 \%$ & $70 \%$ & $87 \%$ \\
\hline Storch, 2008 (retrospective) [87] & $\begin{array}{l}\text { Mediastinal/thoracic lesions } \\
\text { (Transesophageal) }\end{array}$ & 48 & $79 \%$ & $79 \%$ & $98 \%$ \\
\hline Shah, 2008 (retrospective) [95] & $\begin{array}{l}\text { Pancreatic mass } \\
\text { (Transgastric) }\end{array}$ & $123^{3}$ & - & $89 \%$ & $96 \%$ \\
\hline Aithal, 2007 (prospective) [84] & $\begin{array}{l}\text { Various } \\
\text { (Transesophageal, transgastric) }\end{array}$ & 95 & $89 \%$ & $82 \%$ & $93 \%$ \\
\hline Saftoiu, 2007 (prospective) [86] & $\begin{array}{l}\text { Mediastinal masses } \\
\text { (Transesophageal) }\end{array}$ & 30 & $68 \%$ & $74 \%$ & - \\
\hline Wittmann, 2006 (prospective) [64] & $\begin{array}{l}\text { Various } \\
\text { (Transesophageal, transgastric) }\end{array}$ & $159^{4}$ & $73 \%$ & $77 \%$ & $91 \%$ \\
\hline Storch, 2006 (retrospective) [88] & $\begin{array}{l}\text { Various } \\
\text { (Transesophageal, transgastric) }\end{array}$ & 41 & $76 \%$ & $76 \%$ & $95 \%$ \\
\hline
\end{tabular}

In most instances EUS-TCB does not offer advantages over EUSFNA; however, EUS-TCB should be considered when tissue architectural details and immunostaining are required to establish a specific diagnosis (Recommendation grade C).

There is much less experience with EUS-TCB than with EUS-FNA, with around 1250 EUS-TCB procedures reported to date from a few centers. The 19G Quick Core needle, the only needle available for EUS-TCB, is relatively stiff and prone to malfunction when biopsy is attempted in positions that require scope flexion, especially from the duodenum. For that reason most studies excluded patients in whom a transduodenal approach was required. The few studies in which transduodenal EUS-TCB was attempted reported consistently very low technical success rates, ranging between $8 \%$ and $40 \%$ in consecutive patients $[29,84,85]$. In addition, most studies included only patients with target lesions $\geq 20 \mathrm{~mm}[54,86-89]$.

Adequacy rates reported for non-transduodenal EUS-TCB are much higher ( $83 \%-100 \%$ in prospective studies) [29,64, $84-86$, $90-93]$. In the largest series published an adequate sample was obtained in 215 of 239 patients (90\%), with a median of 3 needle passes [93].

In an RCT that compared EUS-TCB vs. EUS-FNA using high negative pressure, the former method provided core specimens more frequently ( $95.3 \%$ vs. $27.8 \%$; $P<0.0001$ ); however, this fact did not translate into better diagnostic accuracy ( $88.3 \%$ vs. $77.8 \% ; P$ $=0.24$ ) [90]. Also other studies that directly compared EUS-TCB and EUS-FNA found no significant difference between these methods in the accuracy for malignancy detection ( $\square$ Table 5 ) $[29,64,84,86-88,90,94,95]$. Dual sampling (EUS-FNA+EUSTCB) was consistently shown to improve accuracy when compared to either technique alone. Because using two needles in one patient is impractical and costly, a sequential approach has been evaluated that involved EUS-TCB with EUS-FNA rescue. The accu- racy of such an approach was similar to that obtained with dual sampling [84]. Rescue EUS-FNA was necessary only in 10\%-11\% of cases in which EUS-TCB failed [84,91]. A reverse approach (EUS-FNA with EUS-TCB rescue) has not been evaluated.

Although not superior to EUS-FNA in detecting malignancy, EUSTCB offers advantages in establishing some specific diagnoses, in particular of benign diseases [86,87,93]. Limited evidence suggests that immunostaining studies can be performed more reliably on EUS-TCB than on EUS-FNA samples [89]. Promising results have been reported from studies evaluating EUS-TCB in conditions in which the diagnosis relies mostly on tissue architectural details and EUS-FNA with cytopathological examination has limited value (autoimmune pancreatitis, non-focal chronic pancreatitis, tuberculosis and sarcoidosis, liver parenchymal disease, lymphoma) [96-100].

The feasibility and yield of sampling with a new histology needle (Echotip ProCore 19G; $\bullet$ Table3) were recently evaluated in a multicenter study involving 109 consecutive patients with 114 lesions (pancreatic masses, lymph nodes and other indications) [101]. Biopsy was successful in all but two cases (98\%). A sample adequate for histopathological evaluation was obtained from $89 \%$ lesions. In the remaining $9 \%$ of cases the sample was adequate for cytopathological evaluation (cell blocks). Sensitivity, specificity, positive predictive value, negative predictive value, and overall accuracy for diagnosis of malignancy were $90.2 \%, 100 \%, 100 \%$, $78.9 \%$, and $92.9 \%$, respectively. No complications were observed. Of note, transduodenal biopsy was successful in 33 of 35 consecutive cases (94\%) which seems to be an important advantage over EUS-TCB. However, direct comparisons of the ProCore needle with other needle types are lacking. 


\section{Specimen processing}

No adequate study has compared direct smear cytology vs. liquidbased cytology (LBC) for processing specimens collected with EUSFNA. Similarly, no study has evaluated which of the methods described for collecting tissue fragments for histopathological examination is better. In the case of suspected tuberculosis or lymphoma, polymerase chain reaction (suspected tuberculosis) on histopathological specimens and flow cytometry (suspected lymphoma), after placement of the collected specimen in an adequate transport medium, have been shown to significantly increase the diagnostic yield (Evidence level 2+). The specific method to be used for both cytopathological processing and collection of histopathological specimens should be left to the discretion of each center, depending on their confidence with available methods (Recommendation grade D). Cell blocks can be used as a complement to rather than a replacement for smears or LBC (Recommendation grade D). If tuberculosis is suspected, then polymerase chain reaction should be used; if lymphoma is suspected, then flow cytometry should be used (Recommendation grade $C$ ).

Because EUS-FNA accuracy may be compromised by inadequate specimens, appropriate processing of samples is crucial. Although a direct smear has traditionally been used for preparing EUS-FNA specimens, other methods are available including LBC, cell block preparation, and EUS-FNA histology.

\subsection{Smears}

Smears may be prepared using the conventional direct smear method or the LBC method. Direct smears are prepared in the endoscopy suite by extruding the needle content onto a glass slide and spreading the material in an evenly thin way. This technique requires a certain level of skill and practice to avoid common pitfalls, including a smear that is too thick (cells obscured within clusters) and air-drying artifacts [102 - 104]. For detailed instruction, readers are referred to recent guidelines [48].

Smears may be allowed to dry or be fixed immediately by spray fixation or immersion into $95 \%$ alcohol. Unfixed smears are a potential biohazard and should be handled accordingly [48]. Airdried and alcohol-fixed direct smears are usually stained using Giemsa and Papanicolaou methods, respectively. Needle washings, preserved in a liquid transport medium, provide additional material for further studies including special stains, immunocytochemistry, microbiological investigations, flow cytometry, or molecular testing [48].

For $\mathrm{LBC}$, the aspirate is transferred into a vial containing a fixative or a transport medium. Smears are then prepared in the laboratory. Importantly, the remainder of the samples should be stored so that it is available for additional preparation that may prove useful after initial cytopathological examination. The various available LBC methods have not been compared in EUS-FNA studies. Therefore, the specific method used should be at the discretion of each pathology laboratory. Thin-layer LBC is an automated process designed to overcome the problems associated with manual preparation of smears described above. This technique has mostly been evaluated in cervical cytology and shown to be equivalent or superior to conventional smear methods in this setting [105]. Data on the use of thin-layer LBC preparations for EUSFNA aspirates are limited and contradictory [22,104, 106 - 108].

\subsection{Cell block}

Cell block is a preparation in which the specimen is centrifuged into a pellet, formalin-fixed, paraffin-embedded, and sectioned for standard staining or ancillary tests such as immunocytochemistry and genetic analysis. Cell blocks can be prepared from leftover material rinsed from the needle after preparation of smears or from material especially obtained for this purpose (by alternating drops of the aspirate for smears and for cell blocks or by performing additional needle passes) [102]. Cell blocks are used as a complement to rather than a replacement for smears.

\subsection{Specimen processing for histology}

Methods described for collecting tissue fragments for histopathological examination from specimens obtained with standard EUS-FNA needles include injection of $2 \mathrm{ml}$ saline through the needle to expel the specimen directly into a fixative $[77,79]$, or expelling the specimen with the needle stylet onto a glass slide or into saline and picking up tissue fragments to immerse them into a fixative $[63,75]$. Tumor tissue is usually whitish; however, red coagula may also contain tumor tissue $[63,75,78]$. Gross visual inspection seems to be a relatively reliable way to confirm that the specimen is adequate for histology; however, false-positive misinterpretation occurs in about $13.5 \%-33 \%$ of cases $[63,76]$. Mean length of the core specimens obtained with EUSFNA is $6.5 \pm 5.3 \mathrm{~mm}$ (range $1-22 \mathrm{~mm}$ ) [77]. Collecting tissue fragments for EUS-FNA histology does not seem to interfere with further cytopathological evaluation of the remaining specimen [ 63 , $76,80]$.

Tissue obtained with EUS-TCB is usually carefully retrieved with a thin injection needle from the specimen notch of the Trucut needle and then placed in buffered formalin and processed in the same way as forceps biopsy specimens. Median length of core specimens obtained with EUS-TCB is $10 \mathrm{~mm}$ (range 2-18); one third of samples are fragmented [93]. Special care should be taken not to lose those tiny specimens during processing.

\subsection{Special handling}

In cases of suspected mycobacterial infection, microbiological confirmation should be obtained before treatment. Therefore, the material from one needle pass should be reserved for specific analysis and adequately fixed according to local protocols. Polymerase chain reaction can be performed on paraffin-embedded material obtained with EUS-guided biopsy to detect mycobacteria if the diagnosis was not suspected initially $[109,110]$. Similarly, in the case of suspected lymphoma, a specimen should be placed in a transport medium adequate for flow cytometry, which has been reported to significantly increase the yield for the diagnosis of lymphoma [111,112].

\section{Complications of EUS-FNA and their prevention \\ $\nabla$}

EUS-FNA is a safe procedure with a complication rate of approximately $1 \%$ (Evidence level $2++$ ). Complications include infection, bleeding, and acute pancreatitis; they are more frequent for EUSFNA of cystic compared with solid lesions (Evidence level 2-). Bacteremia is rare after EUS-FNA, including that of perirectal and rectal lesions (Evidence level 2++). The 19G, 22G, and 25G EUS-FNA needles present similar complication rates. Transesophageal and transgastric EUS-TCB have similar safety profiles compared with EUS-FNA, at least in experienced hands (Evidence level 1-). Aspirin/non-steroidal anti-inflammatory drugs (NSAIDs) do not seem to 
Table 6 Complications of endoscopic ultrasound (EUS)-guided fine needle aspiration (FNA) in selected prospective series.

\begin{tabular}{|llllllll|}
\hline First author, year & Patients, $\mathbf{n}$ & $\begin{array}{l}\text { Follow-up, } \\
\text { days }\end{array}$ & $\begin{array}{l}\text { Lost to } \\
\text { follow-up, } \%\end{array}$ & $\begin{array}{l}\text { Morbidity, } \\
\%\end{array}$ & $\begin{array}{l}\text { Complications after EUS-FNA of: } \\
\text { Fluid collec- } \\
\text { tions }\end{array}$ & $\begin{array}{l}\text { Polid masses } \\
\text { mortality, } \%\end{array}$ \\
\hline Al-Haddad, 2008 [114] & 483 & 30 & 14 & 1.4 & $3 / 83^{1}$ & $4 / 400$ & 0 \\
\hline Bournet, 2006 [115] & $213^{2}$ & 1 & 0 & 2.2 & $1 / 74^{1}$ & $4 / 139$ & 0 \\
\hline Eloubeidi, 2006 [117] & 355 & 3 & 1 & 2.5 & $0 / 0$ & $9 / 355$ & 0 \\
\hline Mortensen, 2005 [113] & $567^{2}$ & No data & No data & 0.4 & $0 / 33^{1}$ & $2 / 534$ & 0.2 \\
\hline Williams, 1999 [57] & 333 & No data & No data & 0.3 & $1 / 20^{1}$ & $0 / 313$ & 0 \\
\hline Bentz, 1998 [116] & 60 & No data & No data & 0 & No data & No data & 0 \\
\hline Wiersema, 1997 [5] & 457 & 30 & 0 & 1.1 & $3 / 22$ & $2 / 435$ & 0 \\
\hline
\end{tabular}

Antibiotic prophylaxis administered.

2 Patients with EUS-guided interventions other than fine needle aspiration were not included in the table.

increase the risk of bleeding following EUS-FNA (Evidence level $2-)$.

Antibiotic prophylaxis is recommended before EUS-guided sampling of cystic lesions (Recommendation grade C) but not of solid lesions (Recommendation grade B). Antibiotic prophylaxis of infective endocarditis is not recommended (Recommendation grade $B$ ). Coagulation check-up is recommended before EUS-FNA only in patients with a personal or family history suggesting bleeding disorder or with a clear clinical indication (Recommendation grade C). EUS-guided sampling should not be performed in patients treated with oral anticoagulants (Recommendation grade $C$ ) or thienopyridines (Recommendation grade D). In addition, treatment with aspirin or NSAIDs is a contraindication for EUS-guided sampling of cystic lesions (Recommendation grade $C$ ).

EUS-TCB is contraindicated for lesions requiring a transduodenal approach, and lesions $<20 \mathrm{~mm}$ or of cystic appearance, and when the operator has limited experience with standard EUS-FNA (Recommendation grade $D$ ).

\subsection{What is the overall risk of complications associated with EUS-FNA?}

EUS-FNA morbidity reported in the prospective series listed in - Table 6 ranged between 0 and 2.5\% (1.2\% in pooled material from all studies); there was one death among 2468 patients $(0.04 \%)[57,59,113-117]$. Complications mostly included infection, bleeding, and acute pancreatitis. Retrospective series tend to under-report complications [118].

\subsection{What are the risk factors for EUS-FNA complications?} Because complications associated with EUS - FNA are very rare, studies would require very large numbers of patients to be adequately powered to evaluate risk factors for complications.

Wiersema et al. reported a significantly higher incidence of complications for EUS-FNA of pancreatic fluid collections than for pancreatic solid lesions (3/22 [14\%] vs. $2 / 452$ [0.5\%], respectively; $P<0.001)$. The complications observed after FNA of fluid collections included two febrile episodes and one pseudocyst hemorrhage; two of these patients required surgery [59]. In all subsequent studies ( Table 6 ), antibiotic prophylaxis was administered before EUS-FNA of pancreatic fluid collections, but in spite of that the overall morbidity remained higher than for solid masses (5/210 [2.4\%] vs. 10/1386 [0.7\%], respectively). Based on these data, a cystic character of the lesion is considered a risk factor for complications, both of infection and bleeding.

A larger needle size does not seem to be associated with a higher complication risk. Two RCTs comparing needles of different sizes
(22G vs. $25 \mathrm{G}$, and $19 \mathrm{G}$ vs. $25 \mathrm{G}$ ) recorded no complications at all $[27,28]$. In another study, the number of needle passes was not associated with the risk of complications [119]. Given the very low risk of EUS-FNA complications, these studies were clearly underpowered to detect a significant difference.

EUS-TCB presents a safety profile similar to that of EUS-FNA, at least in experienced hands. It has to be noted, however, that because of the limited flexibility of the Trucut needle, in most studies EUS-TCB was not performed transduodenally. In addition, only lesions $\geq 2 \mathrm{~cm}$ were usually punctured. An RCT of 77 patients who underwent either EUS-TCB or EUS-FNA (using a 22G needle and high suction pressure) found similar complication rates in both groups (2.3\% vs. $2.8 \%$ ) [90]. Similar complication rates $(1 \%-2.4 \%)$ were reported in two large prospective series of EUS-TCB including 96 and 247 patients, respectively [64, 93]. The latter study suggested that operator experience might be an important factor because all complications were observed among the first 100 patients [93]. Selected small studies have reported higher morbidity rates $(4 \%-12.5 \%$, including complications requiring surgery) $[26,96,120]$.

\subsection{Specific complications and their prevention}

\subsubsection{Infection}

The incidence of bacteremia following EUS-FNA, including EUSFNA of rectal and perirectal lesions, is low $(0 \%-6 \%)$ and similar to that observed after EUS without FNA [121 - 124]. According to recent guidelines, antibiotic prophylaxis is not recommended for the prevention of infective endocarditis in patients with cardiac risk factors who undergo EUS-FNA [125, 126].

Clinical infectious complications after EUS-FNA of solid lesions (including rectal and perirectal lesions) are very rare, with incidences of $0 \%$ to $0.6 \%$ in large prospective series $[57,59,113$ $115,117,123]$. As discussed above it is generally accepted that the higher risk of EUS-FNA in fluid collections warrants antibiotic prophylaxis. Fluoroquinolones administered intravenously before the procedure and orally for 3-5 days thereafter are probably the regimen used most commonly [114,125]; betalactam antibiotics have also been used in this setting $[115,119]$. The incidence of infectious complications in prospective studies that used prophylaxis was low ( $0 \%$ to $1.4 \%$ ) [57,113-115]. In a large retrospective analysis of 603 patients with 651 pancreatic cysts, a single patient $(0.2 \%)$ developed infection [127].

EUS-FNA of mediastinal cysts may be complicated by infection, including life-threatening mediastinitis $[26,128,129]$. For that reason, and because of limited clinical impact, EUS-FNA of simple 
mediastinal cystic lesions is usually considered to be contraindicated $[130,131]$. On the other hand, EUS-FNA might be of value in atypical/complex mediastinal cystic lesions to rule out malignancy. In such cases antibiotic prophylaxis should be administered [132].

\subsubsection{Bleeding}

Clinically significant bleeding is a possible, but very rare complication of EUS-FNA. Only single cases have been reported, including one that was fatal [113]. The incidence reported in large prospective series ranged between $0 \%$ and $0.5 \%[57,59,113-115$, 117]. Self-limited intraprocedural bleeding with no clinical consequences is more common. Extraluminal bleeding (visible as an expanding echopoor region adjacent to the sampled lesion) has been reported to occur during $1.3 \%-2.6 \%$ of procedures [133, $134]$, and intracystic bleeding (gradually expanding hyperechoic area within the cyst) during $6 \%$ of EUS-FNA of pancreatic cysts [135]. In both instances the management consisted in cessation of further needle passes, observation by EUS, and a short course of antibiotics to prevent infection $[133,135]$. The clinical course has been uneventful in all cases. Rare cases of intraprocedural luminal bleeding requiring intervention (adrenaline injection and hemostatic clips) have been described [134]. The true effectiveness of the above measures used in the management of extraluminal or intraluminal bleeding related to EUS-FNA has not been investigated.

Although not evidence-based, platelet count and coagulation check-up are performed before EUS-FNA in most centers, with platelet count $<50000 / \mathrm{mm}^{3}$ and international normalized ratio $>1.5$ considered to be contraindications to EUS-guided sampling $[43,114,130,136]$. Criticisms of this approach include poor sensitivity and specificity for the prediction of postintervention bleeding, costs, and the risk that it might indeed increase rather than decrease the risk of litigation [137]. Recent guidelines recommend the taking of a bleeding history including detail of family history, previous excessive post-traumatic or postsurgical bleeding and use of antithrombotic drugs, and performance of coagulation testing only in patients with a positive history or a clear clinical indication (e.g., liver disease) [137].

Data on EUS-guided sampling in patients undergoing treatment with antithrombotic agents are limited. A prospective controlled study found no increased bleeding risk following EUS-FNA in 26 patients taking aspirin or NSAIDS when compared to 190 controls (overall bleeding rates of $0 \%$ and $3.7 \%$ respectively) [134]. Two of six patients (33\%) on a prophylactic dose of low-molecular weight heparin (LMWH) had clinically non-significant bleeding episodes. Based on these data, and according to published guidelines, the authors recommended that if EUS-guided sampling has to be performed in a patient on LMWH, the procedure should be performed 8 hours or more after administration of the drug $[134,138]$. No data on the risk of EUS-guided sampling in patients treated with thienopyridines are available.

EUS-guided sampling should not be performed in patients taking oral anticoagulants [139]. According to a recently issued ESGE guideline on endoscopy and antiplatelet agents (APA), EUS-FNA of solid masses can be performed in patients taking aspirin or NSAIDS, but not in patients taking thienopyridines (e.g. clopidogrel). EUS-FNA of cystic lesions should not be performed in patients taking APA of any kind [140]. If a change in antithrombotic therapy is required for performance of EUS-FNA, the thromboembolic risk in a given patient and the risk-to-benefit ratio should be considered (for details on the management of antith- rombotic agents for endoscopic procedures, readers are referred to specific guidelines) $[139,140]$.

\subsubsection{Acute pancreatitis}

The reported incidence of acute pancreatitis after EUS-FNA of pancreatic lesions ranged from $0.26 \%$ in a large multicenter survey study to $2 \%$ in a prospective study that specifically searched for this complication in 100 consecutive patients [117,118,134, 141]. Among the 14 cases analyzed in the multicenter survey, pancreatitis was mild, moderate, and severe in 10 (71\%), 3 (21 $\%)$, and 1 (7\%) case, respectively. The median duration of hospitalization for treatment of pancreatitis was 3 days (range 1-21 days). One patient (7\%) with multiple comorbid conditions died as a result of pancreatitis [118]. Factors suggested to predispose to post-EUS-FNA pancreatitis included a history of recent pancreatitis and puncture of a benign pancreatic lesion; however, a significant relationship was not demonstrated [118,141].

\subsubsection{Other complications}

Less frequent complications include esophageal or duodenal perforation [59,113,115], bile peritonitis after FNA of obstructed bile ducts or the gallbladder [142], and seeding of tumorous cells along the needle tract $[143,144]$. The rate of cervical esophagus perforation at the time of intubation with a curvilinear echoendoscope is $0.06 \%$, as assessed in a large prospective study [145]. The perforation risk is higher in stenotic tumors and aggressive attempts at passing the stenosis with the endoscope should be avoided [113]. Bile peritonitis frequently requires surgery and has been reported after inadvertent biliary puncture during EUS-FNA aggravated by subsequent endoscopic retrograde cholangiopancreatography [142]. Three cases of tumor seeding following EUS-FNA have been reported to date $[144,146,147]$; a retrospective study suggests that peritoneal carcinomatosis related to pancreas cancer may occur more frequently after percutaneous compared to EUS-guided FNA [148].

\section{Note \\ $\nabla$}

ESGE guidelines represent a consensus of best practice based on the available evidence at the time of preparation. They may not apply in all situations and should be interpreted in the light of specific clinical situations and resource availability. Further controlled clinical studies may be needed to clarify aspects of these statements, and revision may be necessary as new data appear. Clinical consideration may justify a course of action at variance to these recommendations. ESGE guidelines are intended to be an educational device to provide information that may assist endoscopists in providing care to patients. They are not rules and should not be construed as establishing a legal standard of care or as encouraging, advocating, requiring, or discouraging any particular treatment.

Alberto Larghi and Marc Giovannini have received research support from Cook Endoscopy Inc., Limerick, Ireland. 


\section{Institutions}

Department of Gastroenterology and Hepatology, Medical Centre for Postgraduate Education and Department of Gastroenterology, The M. Sklodowska-Curie Memorial Cancer Center and Institute of Oncology, Warsaw, Poland 2 Digestive Endoscopy Unit, Universita' Cattolica del Sacro Cuore, Rome, Italy CHU Mont-Godinne, Université catholique de Louvain, Yvoir, Belgium

${ }^{4}$ Department of Digestive Endoscopy, Hôpital Saint Joseph, Marseille, France Endoscopic Unit, Paoli-Calmettes Institut, Marseille, France

${ }^{6}$ Department of Gastroenterology, Hôpital Privé Jean Mermoz, Lyon, France Service of Gastroenterology and Hepatology, Geneva University Hospitals, Geneva, Switzerland

\section{Acknowledgment}

$\nabla$

The authors thank Dr. Geneviève Ranchin-Monges for helpful comments.

\section{References}

1 Dumonceau JM, Polkowski M, Larghi A et al. Indications, results and clinical impact of endoscopic ultrasound (EUS)-guided sampling in gastroenterology: European Society of Gastrointestinal Endoscopy (ESGE) Clinical Guideline. Endoscopy 2011; 43: 897-912

2 Dumonceau JM, Riphaus A, Aparicio JR et al. European Society of Gastrointestinal Endoscopy, European Society of Gastroenterology and Endoscopy Nurses and Associates, and the European Society of Anaesthesiology Guideline: Non-anesthesiologist administration of propofol for GI endoscopy. Endoscopy 2010; 42: 960-974

3 Dumonceau JM, Andriulli A, Deviere J et al. European Society of Gastrointestinal Endoscopy (ESGE) Guideline: prophylaxis of post-ERCP pancreatitis. Endoscopy 2010; 42: 503-515

4 Harbour R, Miller J. A new system for grading recommendations in evidence based guidelines. BMJ 2001; 323: 334-336

5 Chang KJ. EUS-guided FNA: the training is moving. Gastrointest Endosc 2004; 59: 69-73

6 Barthet M, Gasmi M, Boustière C et al. EUS training in a live pig model: does it improve echo endoscope hands-on and trainee competence? Endoscopy 2007; 39: 535-539

7 Rösch T. State of the art lecture: endoscopic ultrasonography: training and competence. Endoscopy 2006; 38: 69-72

8 Savides TJ, Fisher AH, Gress FG et al. 1999 ASGE endoscopic ultrasound survey. Gastrointest Endosc 2000; 52: 745 - 750

9 Wasan SM, Kapadia AS, Adler DG. EUS training and practice patterns among gastroenterologists completing training since 1993. Gastrointest Endosc 2005; 62: $914-920$

10 Ho KY. Survey of endoscopic ultrasonographic practice and training in the Asia-Pacific region. J Gastroenterol Hepatol 2006; 21: 1231-1235

11 Das A, Mourad W, Lightdale CJ et al. An international survey of the clinical practice of EUS. Gastrointest Endosc 2004; 60: 765-770

12 Maffei M, Dumortier J, Dumonceau JM. Self-training in unsedated transnasal EGD by endoscopists competent in standard peroral EGD: prospective assessment of the learning curve. Gastrointest Endosc 2008; 67: 410-418

13 Eloubeidi MA, Tamhane A. EUS-guided FNA of solid pancreatic masses: a learning curve with 300 consecutive procedures. Gastrointest Endosc 2005; 61: 700-708

14 Mertz H, Gautam S. The learning curve for EUS-guided FNA of pancreatic cancer. Gastrointest Endosc 2004; 59: 33 - 37

15 Harewood GC, Wiersema LM, Halling AC et al. Influence of EUS training and pathology interpretation on accuracy of EUS-guided fine needle aspiration of pancreatic masses. Gastrointest Endosc 2002; 55: 669673

16 Eisen GM, Dominitz JA, Faigel DO et al. Guidelines for credentialing and granting privileges for endoscopic ultrasound. Gastrointest Endosc 2001; 54: $811-814$

17 Sorbi D, Vazquez-Sequeiros E, Wiersema MJ. A simple phantom for learning EUS-guided FNA. Gastrointest Endosc 2003; 57: 580 - 583

18 Matsuda K, Tajiri H, Hawes RH. How shall we experience EUS and EUSFNA before the first procedure? The development of learning tools. Dig Endosc 2004; 16: 236-239

19 Bussen D, Sailer M, Fuchs KH et al. A teaching model for endorectal ultrasound-guided biopsy and drainage of pararectal tumors. Endoscopy 2004; 36: $217-219$

20 Bhutani MS, Aveyard M, Stills HF. Improved model for teaching interventional EUS. Gastrointest Endosc 2000; 52: 400-403
21 Klapman JB, Logrono R, Dye CE et al. Clinical impact of on-site cytopathology interpretation on endoscopic ultrasound-guided fine needle aspiration. Am J Gastroenterol 2003; 98: 1289-1294

22 LeBlanc JK, Emerson RE, Dewitt J et al. A prospective study comparing rapid assessment of smears and ThinPrep for endoscopic ultrasoundguided fine-needle aspirates. Endoscopy 2010; 42: 389-394

23 Sarker SK, Albrani T, Zaman A et al. Procedural performance in gastrointestinal endoscopy: live and simulated. World J Surg 2010; 34: $1764-1770$

24 Vilmann P, Saftoiu A. Endoscopic ultrasound-guided fine needle aspiration biopsy: equipment and technique. J Gastroenterol Hepatol 2006; 21: $1646-1655$

25 Wiersema MJ, Levy MJ, Harewood GC et al. Initial experience with EUSguided trucut needle biopsies of perigastric organs. Gastrointest Endosc 2002; 56: 275-278

26 Varadarajulu S, Fraig $M$, Schmulewitz $N$ et al. Comparison of EUS-guided 19-gauge Trucut needle biopsy with EUS-guided fine-needle aspiration. Endoscopy 2004; 36: 397-401

27 Siddiqui UD, Rossi F, Rosenthal LS et al. EUS-guided FNA of solid pancreatic masses: a prospective, randomized trial comparing 22-gauge and 25-gauge needles. Gastrointest Endosc 2009; 70: 1093 - 1097

28 Song TJ, Kim JH, Lee SS et al. The prospective randomized, controlled trial of endoscopic ultrasound-guided fine-needle aspiration using $22 \mathrm{G}$ and $19 \mathrm{G}$ aspiration needles for solid pancreatic or peripancreatic masses. Am J Gastroenterol 2010; 105: 1739-1745

29 Sakamoto H, Kitano M, Komaki T et al. Prospective comparative study of the EUS guided 25-gauge FNA needle with the 19-gauge Trucut needle and 22-gauge FNA needle in patients with solid pancreatic masses. J Gastroenterol Hepatol 2009; 24: 384-390

30 YusufTE, Ho S, Pavey DA et al. Retrospective analysis of the utility of endoscopic ultrasound-guided fine-needle aspiration (EUS-FNA) in pancreatic masses, using a 22-gauge or 25-gauge needle system: a multicenter experience. Endoscopy 2009; 41: 445-448

31 Itoi T, Itokawa $F$, Kurihara $T$ et al. Experimental endoscopy: objective evaluation of EUS needles. Gastrointest Endosc 2009; 69: 509-516

32 Bhutani MS, Suryaprasad S, Moezzi J et al. Improved technique for performing endoscopic ultrasound guided fine needle aspiration of lymph nodes. Endoscopy 1999; 31: 550-553

33 Wallace MB, Kennedy T, Durkalski V et al. Randomized controlled trial of EUS-guided fine needle aspiration techniques for the detection of malignant lymphadenopathy. Gastrointest Endosc 2001; 54: 441 - 447

34 Puri R, Vilmann P, Săftoiu A et al. Randomized controlled trial of endoscopic ultrasound-guided fine-needle sampling with or without suction for better cytological diagnosis. Scand J Gastroenterol 2009; 44: 499-504

35 Larghi A, Noffsinger A, Dye C et al. EUS-guided fine needle tissue acquisition by using high negative pressure suction for the evaluation of solid masses: a pilot study. Gastrointest Endosc 2005; 62: 768 - 774

36 Rastogi A, Wani S, Gupta $N$ et al. A prospective, single-blind, randomized, controlled trial of EUS-guided FNA with and without a stylet. Gastrointest Endosc 2011; 74: 58 - 64

37 Wani S, Gupta N, Gaddam S et al. A comparative study of endoscopic ultrasound guided fine needle aspiration with and without a stylet. Dig Dis Sci 2011: 56: 2409-2414

38 Sahai AV, Paquin SC, Gariépy G. A prospective comparison of endoscopic ultrasound-guided fine needle aspiration results obtained in the same lesion, with and without the needle stylet. Endoscopy 2010; 42: $900-903$

39 Dumonceau JM. Should we discard the needle stylet during EUS-FNA? Endoscopy 2011; 43: 167

40 Napoleon B, Alvarez-Sanchez MV, Gincoul $R$ et al. Contrast-enhanced harmonic endoscopic ultrasound in solid lesions of the pancreas: results of a pilot study. Endoscopy 2010; 42: 564-570

41 Giovannini M, Thomas B, Erwan B et al. Endoscopic ultrasound elastography for evaluation of lymph nodes and pancreatic masses: a multicenter study. World J Gastroenterol 2009; 15: 1587-1593

42 Rogart JN, Loren DE, Singu BS et al. Cyst wall puncture and aspiration during EUS-guided fine needle aspiration may increase the diagnostic yield of mucinous cysts of the pancreas. J Clin Gastroenterol 2011; 45: $164-169$

43 Al-Haddad M, Gill KR, Raimondo $M$ et al. Safety and efficacy of cytology brushings versus standard fine-needle aspiration in evaluating cystic pancreatic lesions: a controlled study. Endoscopy 2010; 42: 127-132 
44 Thomas T, Bebb J, Mannath J et al. EUS-guided pancreatic cyst brushing: a comparative study in a tertiary referral centre. JOP 2010; 11 : 163 169

45 Sendino O, Fernández-Esparrach G, Solé $M$ et al. Endoscopic ultrasonography-guided brushing increases cellular diagnosis of pancreatic cysts: A prospective study. Dig Liver Dis 2010; 42: 877-881

46 Al-Haddad M, Raimondo M, Woodward T et al. Safety and efficacy of cytology brushings versus standard FNA in evaluating cystic lesions of the pancreas: a pilot study. Gastrointest Endosc 2007; 65: 894-898

47 Nguyen YP, Maple JT, Zhang $Q$ et al. Reliability of gross visual assessment of specimen adequacy during EUS-guided FNA of pancreatic masses. Gastrointest Endosc 2009; 69: 1264-1270

48 Kocjan G, Chandra A, Cross P et al. BSCC Code of Practice - fine needle aspiration cytology. Cytopathology 2009; 20: 283-296

49 Nasuti JF, Gupta PK, Baloch ZW. Diagnostic value and cost-effectiveness of on-site evaluation of fine-needle aspiration specimens: review of 5,688 cases. Diagn Cytopathol 2002; 27: 1 -4

50 Woon C, Bardales RH, Stanley MWet al. Rapid assessment of fine needle aspiration and the final diagnosis - how often and why the diagnoses are changed. Cytojournal 2006; 3: 25

51 Chang KJ, Katz KD, Durbin TE et al. Endoscopic ultrasound-guided fineneedle aspiration. Gastrointest Endosc 1994; 40: 694-699

52 Erickson RA, Sayage-Rabie L, Beissner RS. Factors predicting the number of EUS-guided fine-needle passes for diagnosis of pancreatic malignancies. Gastrointest Endosc 2000; 51: 184 - 190

53 Savides TJ, Donohue M, Hunt G et al. EUS-guided FNA diagnostic yield of malignancy in solid pancreatic masses: a benchmark for quality performance measurement. Gastrointest Endosc 2007; 66: 277-282

54 Eloubeidi MA, Jhala D, Chhieng DC et al. Yield of endoscopic ultrasoundguided fine-needle aspiration biopsy in patients with suspected pancreatic carcinoma. Cancer 2003; 99: 285-292

55 Gress FG, Hawes RH, Savides TJ et al. Endoscopic ultrasound-guided fine-needle aspiration biopsy using linear array and radial scanning endosonography. Gastrointest Endosc 1997; 45: 243 - 250

56 Jhala NC, Jhala D, Eltoum I et al. Endoscopic ultrasound-guided fineneedle aspiration biopsy: a powerful tool to obtain samples from small lesions. Cancer 2004; 102: 239-246

57 Williams DB, Sahai AV, Aabakken L et al. Endoscopic ultrasound guided fine needle aspiration biopsy: a large single centre experience. Gut 1999; 44: $720-726$

58 Eloubeidi MA, Tamhane A, Jhala $N$ et al. Agreement between rapid onsite and final cytologic interpretations of EUS-guided FNA specimens implications for the endosonographer and patient management. Am J Gastroenterol 2006; 101: 2841 - 2847

59 Wiersema MJ, Vilmann P, Giovannini $M$ et al. Endosonography-guided fine-needle aspiration biopsy: diagnostic accuracy and complication assessment. Gastroenterology 1997; 112: 1087-1095

60 Cleveland P, Gill KRS, Coe SG et al. An evaluation of risk factors for inadequate cytology in EUS-guided FNA of pancreatic tumors and lymph nodes. Gastrointest Endosc 2010; 71: 1194-1199

61 Iglesias-Garcia J, Dominguez-Munoz JE, Abdulkader I et al. Influence of on-site cytopathology evaluation on the diagnostic accuracy of endoscopic ultrasound-guided fine needle aspiration (EUS-FNA) of solid pancreatic masses. Am J Gastroenterol 2011; 106: 1705-1710

62 Cherian PT, Mohan P, Douiri A et al. Role of endoscopic ultrasoundguided fine-needle aspiration in the diagnosis of solid pancreatic and peripancreatic lesions: is onsite cytopathology necessary? HPB (Oxford) 2010; $12: 389-395$

63 Moller K, Papanikolaou IS, Toermer T et al. EUS-guided FNA of solid pancreatic masses: high yield of 2 passes with combined histologic-cytologic analysis. Gastrointest Endosc 2009; 70: 60-69

64 Wittmann J, Kocjan G, Sgouros SN et al. Endoscopic ultrasound-guided tissue sampling by combined fine needle aspiration and trucut needle biopsy: a prospective study. Cytopathology 2006; 17: 27 - 33

65 Pellisé Urquiza M, Fernández-Esparrach G, Solé M et al. Endoscopic ultrasound-guided fine needle aspiration: predictive factors of accurate diagnosis and cost-minimization analysis of on-site pathologist. Gastroenterol Hepatol 2007; 30: 319-324

66 Layfield LJ, Bentz JS, Gopez EV. Immediate on-site interpretation of fineneedle aspiration smears: a cost and compensation analysis. Cancer 2001; 93: 319-322

67 Savoy $A D$, Raimondo $M$, Woodward TA et al. Can endosonographers evaluate on-site cytologic adequacy? A comparison with cytotechnologists. Gastrointest Endosc 2007; 65: 953 - 957
68 Hikichi T, Irisawa A, Bhutani MS et al. Endoscopic ultrasound-guided fine-needle aspiration of solid pancreatic masses with rapid on-site cytological evaluation by endosonographers without attendance of cytopathologists. J Gastroenterol 2009; 44: 322 - 328

69 LeBlanc JK, Ciaccia D, Al-Assi MT et al. Optimal number of EUS-guided fine needle passes needed to obtain a correct diagnosis. Gastrointest Endosc 2004; 59: 475-481

70 Turner BG, Cizginer S, Agarwal D et al. Diagnosis of pancreatic neoplasia with EUS and FNA: a report of accuracy. Gastrointest Endosc 2010; 71: $91-98$

71 Hoda KM, Rodriguez SA, Faigel DO. EUS-guided sampling of suspected GI stromal tumors. Gastrointest Endosc 2009; 69: 1218-1223

72 Mekky MA, Yamao K, Sawaki A et al. Diagnostic utility of EUS-guided FNA in patients with gastric submucosal tumors. Gastrointest Endosc 2010; 71: 913 -919

73 Nguyen P, Feng JC, Chang KJ. Endoscopic ultrasound (EUS) and EUSguided fine-needle aspiration (FNA) of liver lesions. Gastrointest Endosc 1999; 50: $357-361$

74 Singh P, Mukhopadhyay P, Bhatt B et al. Endoscopic ultrasound versus CT scan for detection of the metastases to the liver: results of a prospective comparative study. J Clin Gastroenterol 2009; 43: 367 - 373

75 Yoshida S, Yamashita K, Yokozawa M et al. Diagnostic findings of ultrasound-guided fine-needle aspiration cytology for gastrointestinal stromal tumors: proposal of a combined cytology with newly defined features and histology diagnosis. Pathol Int 2009; 59: 712 - 719

76 Papanikolaou IS, Adler A, Wegener K et al. Prospective pilot evaluation of a new needle prototype for endoscopic ultrasonography-guided fine-needle aspiration: comparison of cytology and histology yield Eur J Gastroenterol Hepatol 2008; 20: 342 - 348

77 Iglesias-Garcia J, Dominguez-Munoz E, Lozano-Leon A et al. Impact of endoscopic ultrasound-guided fine needle biopsy for diagnosis of pancreatic masses. World J Gastroenterol 2007; 13: 289-293

78 Yasuda I, Tsurumi H, Omar S et al. Endoscopic ultrasound-guided fineneedle aspiration biopsy for lymphadenopathy of unknown origin. Endoscopy 2006; 38: 919-924

79 Voss M, Hammel P, Molas G et al. Value of endoscopic ultrasound guided fine needle aspiration biopsy in the diagnosis of solid pancreatic masses. Gut 2000; 46: 244-249

80 Ardengh JC, Paulo GA, Nakao FS et al. Endoscopic ultrasound guided fine-needle aspiration core biopsy: comparison between an automatic biopsy device and two conventional needle systems. Acta Gastroenterol Latinoam 2008; 38: 105-115

81 Turhan N, Aydog G, Ozin Y et al. Endoscopic ultrasonography-guided fine-needle aspiration for diagnosing upper gastrointestinal submucosal lesions: A prospective study of 50 cases. Diagn Cytopathol 2011; 39: $808-817$

82 Ando N, Goto H, Niwa Y et al. The diagnosis of GI stromal tumors with EUS-guided fine needle aspiration with immunohistochemical analysis. Gastrointest Endosc 2002; 55: $37-43$

83 Akahoshi K, Sumida Y, Matsui N et al. Preoperative diagnosis of gastrointestinal stromal tumor by endoscopic ultrasound-guided fine needle aspiration. World J Gastroenterol 2007; 13: 2077-2082

84 Aithal GP, Anagnostopoulos GK, Tam W et al. EUS-guided tissue sampling: comparison of "dual sampling" (Trucut biopsy plus FNA) with "sequential sampling" (Trucut biopsy and then FNA as required). Endoscopy 2007; 39: 725-730

85 Larghi A, Verna EC, Stavropoulos SN et al. EUS-guided trucut needle biopsies in patients with solid pancreatic masses: a prospective study. Gastrointest Endosc 2004; 59: 185 - 190

86 Saftoiu A, Vilmann P, Guldhammer Skov B et al. Endoscopic ultrasound (EUS)-guided Trucut biopsy adds significant information to EUS-guided fine-needle aspiration in selected patients: a prospective study. Scand J Gastroenterol 2007; 42: 117-125

87 Storch I, Shah M. Thurer $R$ et al. Endoscopic ultrasound-guided fineneedle aspiration and Trucut biopsy in thoracic lesions: when tissue is the issue. Surg Endosc 2008; 22: 86-90

88 Storch I, Jorda M, Thurer $R$ et al. Advantage of EUS Trucut biopsy combined with fine-needle aspiration without immediate on-site cytopathologic examination. Gastrointest Endosc 2006; 64: 505 - 511

89 Fernández-Esparrach $G$, Sendino 0 , Solé $M$ et al. Endoscopic ultrasoundguided fine-needle aspiration and trucut biopsy in the diagnosis of gastric stromal tumors: a randomized crossover study. Endoscopy 2010; 42: $292-299$ 
90 Gerke H, Rizk MK, Vanderheyden $A D$ et al. Randomized study comparing endoscopic ultrasound-guided Trucut biopsy and fine needle aspiration with high suction. Cytopathology 2010; 21: 44-51

91 Gines A, Wiersema MJ, Clain JE et al. Prospective study of a Trucut needle for performing EUS-guided biopsy with EUS-guided FNA rescue. Gastrointest Endosc 2005; 62: 597 -601

92 Thomas T, Kaye PV, Ragunath $K$ et al. Endoscopic-ultrasound-guided mural trucut biopsy in the investigation of unexplained thickening of esophagogastric wall. Endoscopy 2009; 41: 335 - 339

93 Thomas T, Kaye PV, Ragunath K et al. Efficacy, safety, and predictive factors for a positive yield of EUS-guided Trucut biopsy: a large tertiary referral center experience. Am J Gastroenterol 2009; 104: 584- 591

94 Kipp BR, Pereira TC, Souza PC et al. Comparison of EUS-guided FNA and Trucut biopsy for diagnosing and staging abdominal and mediastinal neoplasms. Diagnostic cytopathology 2009; 37: 549-556

95 Shah SM, Ribeiro A, Levi J et al. EUS-guided fine needle aspiration with and without trucut biopsy of pancreatic masses. JOP 2008; 9: 422 -430

96 Dewitt J, McGreevy K, Leblanc J et al. EUS-guided Trucut biopsy of suspected nonfocal chronic pancreatitis. Gastrointest Endosc 2005; 62: $76-84$

97 Gleeson FC, Clayton AC, Zhang L et al. Adequacy of endoscopic ultrasound core needle biopsy specimen of nonmalignant hepatic parenchymal disease. Clin Gastroenterol Hepatol 2008; 6: 1437-1440

98 Mizuno N, Bhatia $V$, Hosoda $W$ et al. Histological diagnosis of autoimmune pancreatitis using EUS-guided trucut biopsy: a comparison study with EUS-FNA. J Gastroenterol 2009; 44: 742 - 750

99 Song HJ, Park YS, Seo DW et al. Diagnosis of mediastinal tuberculosis by using EUS-guided needle sampling in a geographic region with an intermediate tuberculosis burden. Gastrointest Endosc 2010; 71: 1307 1313

100 Eloubeidi MA, Mehra M, Bean SM. EUS-guided 19-gauge trucut needle biopsy for diagnosis of lymphoma missed by EUS-guided FNA. Gastrointest Endosc 2007; 65: 937-939

101 Iglesias-Garcia J, Poley J-W, Larghi A et al. Feasibility and yield of a new EUS histology needle: results from a multicenter, pooled, cohort study. Gastrointest Endosc 2011; 73: 1189-1196

102 Behling C. A cytology primer for endosonographers. In: Hawes RH, Fockens P eds. Endosonography. Philadelphia: Saunders Elsevier; 2006: 273-291

103 de Luna R, Eloubeidi MA, Sheffield MV et al. Comparison of ThinPrep and conventional preparations in pancreatic fine-needle aspiration biopsy. Diagn Cytopathol 2004; 30: 71 - 76

104 Wallace WA, Monaghan HM, Salter DM et al. Endobronchial ultrasound-guided fine-needle aspiration and liquid-based thin-layer cytology. J Clin Pathol 2007; 60: 388 - 391

105 Arbyn M, Bergeron C, Klinkhamer P et al. Liquid compared with conventional cervical cytology: a systematic review and meta-analysis. Obstet Gynecol 2008; 111: 167-177

106 Fabre M, Ben-Lagha N, Palazzo L. La cytologie en milieu liquide peutelle remplacer la cytologie conventionnelle pour le diagnostic des ponctions a l'aiguille fine sous échoendoscopie? Résultats d'une étude prospective multicentrique [abstract]. Gastroenterol Clin Biol 2003; 27: A66

107 Meara RS, Jhala D, Eloubeidi MA et al. Endoscopic ultrasound-guided FNA biopsy of bile duct and gallbladder: analysis of 53 cases. Cytopathology 2006; 17: $42-49$

108 Rossi ED, Larghi A, Verna EC et al. Endoscopic ultrasound-guided fineneedle aspiration with liquid-based cytologic preparation in the diagnosis of primary pancreatic lymphoma. Pancreas 2010; 39: 1299 1302

109 Berzosa M, Tsukayama DT, Davies SF et al. Endoscopic ultrasoundguided fine-needle aspiration for the diagnosis of extra-pulmonary tuberculosis. Int J Tuberc Lung Dis 2010; 14: 578 - 584

110 Michael $H$, Ho S, Pollack $B$ et al. Diagnosis of intra-abdominal and mediastinal sarcoidosis with EUS-guided FNA. Gastrointest Endosc 2008; 67: $28-34$

111 Khashab M, Mokadem M, Dewitt J et al. Endoscopic ultrasound-guided fine-needle aspiration with or without flow cytometry for the diagnosis of primary pancreatic lymphoma - a case series. Endoscopy 2010; 42: 228-231

112 Ribeiro A, Pereira D, Escalón MP et al. EUS-guided biopsy for the diagnosis and classification of lymphoma. Gastrointest Endosc 2010; 71: $851-855$

113 Mortensen MB, Fristrup C, Holm FS et al. Prospective evaluation of patient tolerability, satisfaction with patient information, and compli- cations in endoscopic ultrasonography. Endoscopy 2005; 37: 146 153

114 Al-Haddad M, Wallace MB, Woodward TA et al. The safety of fine-needle aspiration guided by endoscopic ultrasound: a prospective study. Endoscopy 2008; 40: 204-208

115 Bournet B, Migueres I, Delacroix M et al. Early morbidity of endoscopic ultrasound: 13 years' experience at a referral center. Endoscopy 2006; 38: 349 - 354

116 Bentz JS, Kochman ML, Faigel DO et al. Endoscopic ultrasound-guided real-time fine-needle aspiration: clinicopathologic features of 60 patients. Diagn Cytopathol 1998; 18: 98 -109

117 Eloubeidi MA, Tamhane A, Varadarajulu $S$ et al. Frequency of major complications after EUS-guided FNA of solid pancreatic masses: a prospective evaluation. Gastrointest Endosc 2006; 63: 622 - 629

118 Eloubeidi MA, Gress FG, Savides TJ et al. Acute pancreatitis after EUSguided FNA of solid pancreatic masses: a pooled analysis from EUS centers in the United States. Gastrointest Endosc 2004; 60: 385 - 389

119 O'Toole D, Palazzo L, Arotçarena $R$ et al. Assessment of complications of EUS-guided fine-needle aspiration. Gastrointest Endosc 2001; 53: 470-474

120 Polkowski M, Gerke W, Jarosz D et al. Diagnostic yield and safety of endoscopic ultrasound-guided trucut biopsy in patients with gastric submucosal tumors: a prospective study. Endoscopy 2009; 41: 329 334

121 Janssen J, König K, Knop-Hammad $V$ et al. Frequency of bacteremia after linear EUS of the upper GI tract with and without FNA. Gastrointest Endosc 2004; 59: 339-344

122 Barawi M, Gottlieb $K$, Cunha $B$ et al. A prospective evaluation of the incidence of bacteremia associated with EUS-guided fine-needle aspiration. Gastrointest Endosc 2001; 53: 189-192

123 Levy MJ, Norton ID, Clain JE et al. Prospective study of bacteremia and complications with EUS FNA of rectal and perirectal lesions. Clin Gastroenterol Hepatol 2007; 5: 684-689

124 Levy MJ, Norton ID, Wiersema MJ et al. Prospective risk assessment of bacteremia and other infectious complications in patients undergoing EUS-guided FNA. Gastrointest Endosc 2003; 57: 672 - 678

125 Banerjee S, Shen B, Baron TH et al. Antibiotic prophylaxis for GI endoscopy. Gastrointest Endosc 2008; 67: 791 - 798

126 Allison MC, Sandoe JAT, Tighe $R$ et al. Antibiotic prophylaxis in gastrointestinal endoscopy. Gut 2009; 58: 869-880

127 Lee LS, Saltzman JR, Bounds BC et al. EUS-guided fine needle aspiration of pancreatic cysts: a retrospective analysis of complications and their predictors. Clin Gastroenterol Hepatol 2005; 3: 231-236

128 Aerts JGJV, Kloover J, Los J et al. EUS-FNA of enlarged necrotic lymph nodes may cause infectious mediastinitis. J Thorac Oncol 2008; 3: $1191-1193$

129 Annema JT, Veselic M, Versteegh MI et al. Mediastinitis caused by EUSFNA of a bronchogenic cyst. Endoscopy 2003; 35: 791 - 793

130 Jenssen C, Dietrich CF. Endoscopic ultrasound-guided fine-needle aspiration biopsy and trucut biopsy in gastroenterology - An overview. Best Pract Res Clin Gastroenterol 2009; 23: 743 - 759

131 Erickson RA. EUS-guided FNA. Gastrointest Endosc 2004; 60: 267 279

132 Fazel A, Moezardalan K, Varadarajulu S et al. The utility and the safety of EUS-guided FNA in the evaluation of duplication cysts. Gastrointest Endosc 2005; 62: 575 - 580

133 Affi A, Vazquez-Sequeiros E, Norton ID et al. Acute extraluminal hemorrhage associated with EUS-guided fine needle aspiration: frequency and clinical significance. Gastrointest Endosc 2001; 53: $221-225$

134 Kien-Fong VuC, Chang F, Doig L et al. A prospective control study of the safety and cellular yield of EUS-guided FNA or Trucut biopsy in patients taking aspirin, nonsteroidal anti-inflammatory drugs, or prophylactic low molecular weight heparin. Gastrointest Endosc 2006; 63: $808-813$

135 Varadarajulu S, Eloubeidi MA. Frequency and significance of acute intracystic hemorrhage during EUS-FNA of cystic lesions of the pancreas. Gastrointest Endosc 2004; 60: 631-635

136 Brugge WR, Lewandrowski K, Lee-Lewandrowski E et al. Diagnosis of pancreatic cystic neoplasms: a report of the cooperative pancreatic cyst study. Gastroenterology 2004; 126: 1330-1336

137 Chee Y, Crawford J, Watson $H$ et al. Guidelines on the assessment of bleeding risk prior to surgery or invasive procedures. Br J Haematol 2008; 140: 496-504 
138 Zuckerman MJ, Hirota WK, Adler DG et al. ASGE guideline: the management of low-molecular-weight heparin and nonaspirin antiplatelet agents for endoscopic procedures. Gastrointest Endosc 2005; 61: 189-194

139 Anderson MA, Ben-Menachem T, Gan SI et al. Management of antithrombotic agents for endoscopic procedures. Gastrointest Endosc 2009; 70: 1060 - 1070

140 Boustière C, Veitch A, Vanbiervliet G et al. Endoscopy and antiplatelet agents. European Society of Gastrointestinal Endoscopy (ESGE) Guideline. . Endoscopy 2011; 43: 445-461

141 Gress F, Michael H, Gelrud D et al. EUS-guided fine-needle aspiration of the pancreas: evaluation of pancreatitis as a complication. Gastrointest Endosc 2002; 56: 864-867

142 Di Matteo F, Shimpi L, Gabbrielli A et al. Same-day endoscopic retrograde cholangiopancreatography after transduodenal endoscopic ultrasound-guided needle aspiration: do we need to be cautious? Endoscopy 2006; 38: 1149-1151

143 Hirooka $Y$, Goto $\mathrm{H}$, Itoh $\mathrm{A}$ et al. Case of intraductal papillary mucinous tumor in which endosonography-guided fine-needle aspiration biopsy caused dissemination. J Gastroenterol Hepatol 2003; 18 : $1323-1324$

144 Paquin SC, Gariépy G, Lepanto L et al. A first report of tumor seeding because of EUS-guided FNA of a pancreatic adenocarcinoma. Gastrointest Endosc 2005; 61: 610-611

145 Eloubeidi MA, Tamhane A, Lopes TL et al. Cervical esophageal perforations at the time of endoscopic ultrasound: a prospective evaluation of frequency, outcomes, and patient management. Am J Gastroenterol 2009; 104: $53-56$

146 Doi S, Yasuda I, Iwashita T et al. Needle tract implantation on the esophageal wall after EUS-guided FNA of metastatic mediastinal lymphadenopathy. Gastrointest Endosc 2008; 67: 988-990

147 Shah JN, Fraker D, Guerry D et al. Melanoma seeding of an EUS-guided fine needle track. Gastrointest Endosc 2004; 59: 923-924

148 Micames C, Jowell PS, White R et al. Lower frequency of peritoneal carcinomatosis in patients with pancreatic cancer diagnosed by EUSguided FNA vs. percutaneous FNA. . Gastrointest Endosc 2003; 58 : $690-695$

\section{Appendix 1 and 2 are available online:}

online content viewable at:

www.thieme-connect.de/ejournals/abstract/endoscopy/ doi/10.1055/s-0031-1291543 
Appendix e1 Topics, key questions and task forces.

\begin{tabular}{|c|c|}
\hline Topics and key questions & $\begin{array}{l}\text { Task force } \\
\text { (spokespersons } \\
\text { in bold) }\end{array}$ \\
\hline \multicolumn{2}{|l|}{ Task force I Learning EUS-FNA } \\
\hline $\begin{array}{l}\text { - Who are adequate candidates to learn } \\
\text { EUS-FNA? } \\
\text { - How can EUS-FNA be learned (dummies, animal } \\
\text { models, mentorship)? } \\
\text { - Which is the learning curve of EUS-FNA? } \\
\text { - Do we recommend a minimum number of } \\
\text { supervised procedures? }\end{array}$ & $\begin{array}{l}\text { J.-M. Dumonceau } \\
\text { B. Pujol }\end{array}$ \\
\hline \multicolumn{2}{|l|}{ Task force II Techniques of EUS-FNA } \\
\hline $\begin{array}{l}\text { - List existing types and diameters of needles } \\
\text { - Which needle diameter is recommended, with } \\
\text { reference to diagnostic yield, complications, } \\
\text { ease of use depending on the location of the } \\
\text { lesion? } \\
\text { - Should suction be applied during EUS-FNA? } \\
\text { - With or without needle stylet? } \\
\text { - Which part of the lesion should be punctured to } \\
\text { maximize the diagnostic yield? } \\
\text { - What is the role of rapid on-site cytopathologi- } \\
\text { cal evaluation (ROSE)? } \\
\text { - How many passes should be performed if ROSE } \\
\text { is not available? }\end{array}$ & $\begin{array}{l}\text { M. Giovannini } \\
\text { M. Polkowski } \\
\text { A. Larghi } \\
\text { J-M. Dumonceau }\end{array}$ \\
\hline \multicolumn{2}{|l|}{$\begin{array}{l}\text { Task force III Techniques for obtaining tissue for } \\
\text { histopathological evaluation }\end{array}$} \\
\hline $\begin{array}{l}\text { - Should tissue fragments be isolated from EUS- } \\
\text { FNA specimens and processed for histology? If } \\
\text { so, how to handle them? } \\
\text { - What is the role of EUS-guided Trucut biopsy? }\end{array}$ & $\begin{array}{l}\text { M. Polkowski } \\
\text { J.-M. Dumonceau }\end{array}$ \\
\hline \multicolumn{2}{|l|}{ Task force IV Specimen processing } \\
\hline $\begin{array}{l}\text { - How do smears and liquid preservation } \\
\text { medium compare (ease, diagnostic yield, cost, } \\
\text { possibility of cell block and of immunostain- } \\
\text { ing)? Do we recommend doing one technique } \\
\text { or both techniques? } \\
\text { - How to prepare smears } \\
\text { - Role of cell blocks } \\
\text { - Specimens processed for histology } \\
\text { - Special handling (culture, PCR, flow cyto- } \\
\text { metry): in which cases and how to do it? }\end{array}$ & $\begin{array}{l}\text { M. Polkowski } \\
\text { B. Weynand } \\
\text { J.-M. Dumonceau }\end{array}$ \\
\hline \multicolumn{2}{|l|}{$\begin{array}{l}\text { Task force } \mathbf{V} \text { Complications of FNA and their } \\
\text { prevention }\end{array}$} \\
\hline $\begin{array}{l}\text { - List type and incidence of complications } \\
\text { - Do some technical factors influence the } \\
\text { complications rate (e. g., needle and endo- } \\
\text { scope type, nature and location of the mass)? } \\
\text { - Should a coagulation check-up be obtained } \\
\text { before FNA? } \\
\text { - How to manage anticoagulation and anti- } \\
\text { platelet treatments? } \\
\text { - In which cases are antibiotic prophylaxis } \\
\text { indicated? } \\
\text { - Specific complications and their prevention }\end{array}$ & $\begin{array}{l}\text { J.-M. Dumonceau } \\
\text { C. Boustière }\end{array}$ \\
\hline
\end{tabular}

EUS, endoscopic ultraosund; FNA, fine needle aspiration; TCB, Trucut biopsy; PCR, polymerase chain reaction

\begin{tabular}{|c|c|c|}
\hline Task force (topic) & $\begin{array}{l}\text { Number of reviewed } \\
\text { references according } \\
\text { to predefined key } \\
\text { questions }\end{array}$ & $\begin{array}{l}\text { Number of rele- } \\
\text { vant references for } \\
\text { the guideline after } \\
\text { evaluation }\end{array}$ \\
\hline $\begin{array}{l}\text { Task force I (Learning } \\
\text { EUS-FNA) }\end{array}$ & 25 & 16 \\
\hline $\begin{array}{l}\text { Task force II (Techniques } \\
\text { of EUS-FNA) }\end{array}$ & 100 & 49 \\
\hline $\begin{array}{l}\text { Task force III (Techniques } \\
\text { for obtaining tissue for } \\
\text { histopathological evalua- } \\
\text { tion) }\end{array}$ & 86 & 28 \\
\hline $\begin{array}{l}\text { Task force IV (Specimen } \\
\text { processing) }\end{array}$ & 40 & 23 \\
\hline $\begin{array}{l}\text { Task force V (Complica- } \\
\text { tions of FNA and their } \\
\text { prevention) }\end{array}$ & 115 & 35 \\
\hline
\end{tabular}

EUS, endoscopic ultrasound; FNA, fine needle aspiration 